TI 2017-036/VIII

Tinbergen Institute Discussion Paper

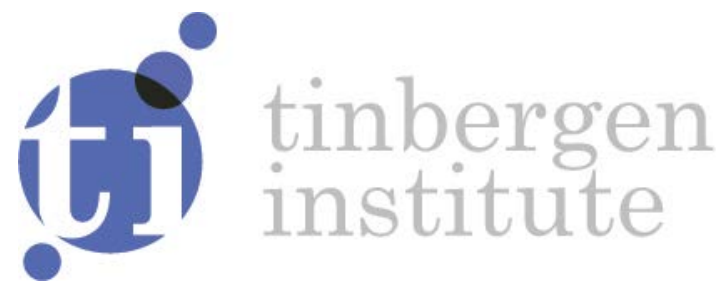

\title{
Buyouts and Agglomeration Bonuses in Wildlife Corridor Auctions
}

\author{
Justin Dijk $k^{1,2}$ \\ Erik Ansink ${ }^{3,4}$ \\ Daan van Soest ${ }^{5}$
}

1 Institute for Environmental Studies, Vrije Universiteit Amsterdam, The Netherlands 2 PBL Netherlands Environmental Assessment Agency, The Hague, The Netherlands

3 Department of Spatial Economics, Vrije Universiteit Amsterdam and Tinbergen Institute, The Netherlands 4 Department of Economic and Social History, Utrecht University, The Netherlands 5 Department of Economics and CentER, Tilburg University, The Netherlands 
Tinbergen Institute is the graduate school and research institute in economics of Erasmus University Rotterdam, the University of Amsterdam and VU University Amsterdam.

Contact: discussionpapers@tinbergen.nl

More TI discussion papers can be downloaded at http://www.tinbergen.nl

Tinbergen Institute has two locations:

Tinbergen Institute Amsterdam

Gustav Mahlerplein 117

1082 MS Amsterdam

The Netherlands

Tel.: +31(0)20 5984580

Tinbergen Institute Rotterdam

Burg. Oudlaan 50

3062 PA Rotterdam

The Netherlands

Tel.: +31(0)10408 8900 


\title{
Buyouts and Agglomeration Bonuses in Wildlife Corridor Auctions*
}

\author{
Justin Dijk ${ }^{\mathrm{a}, \mathrm{b}}$, Erik Ansink $^{\mathrm{c}, \mathrm{d}}$ and Daan van Soest ${ }^{\mathrm{e}}$ \\ ${ }^{a}$ Institute for Environmental Studies, VU University Amsterdam \\ ${ }^{b}$ PBL Netherlands Environmental Assessment Agency, The Hague \\ ${ }^{\mathrm{c}}$ Department of Spatial Economics, VU University Amsterdam \\ ${ }^{\mathrm{d}}$ Department of Economic and Social History, Utrecht University \\ ${ }^{\mathrm{e}}$ Department of Economics and CentER, Tilburg University
}

\begin{abstract}
We present a general model of bidding behavior in wildlife corridor auctions. Given (i) some spatial configuration of landowners in a landscape, (ii) the landowners' opportunity costs, and (iii) the value of establishing the corridor, our model predicts individual landowners' bids, overall participation rates in the auction, as well as the expected net benefits to the conservation agency. We find that market efficiency of the auction increases in the number of potential corridors. We use simulations to compare a benchmark auction with two policy scenarios in a hypothetical landscape. In one scenario, members of a winning corridor receive an agglomeration bonus. In the other scenario, we buy out a pivotal landowner (one that is part of many potential corridors) prior to the auction. Given equal budgets for the agglomeration bonus and the buyout policy, an agglomeration bonus is less efficient than a buyout for conservation agencies facing low budgets, and vice versa. A risk-averse conservation agency is however always better off using a buyout policy.
\end{abstract}

Keywords: Wildlife corridors, procurement auctions, nature conservation programs, agglomeration bonus, buyout.

JEL codes: D44, D85, H57, Q57.

* Corresponding author: Justin Dijk, Telephone: +31 6 11381479; E-mail address: justin.dijk@vu.nl. 


\section{Introduction}

Discriminatory price procurement auctions are a cost-effective method for the procurement of environmental services (Latacz-Lohmann and van der Hamsfoort 1998, Stoneham et al. 2003). In principle, these auctions allow a conservation agency to purchase a specific amount of goods and services at lower expense than, for example, uniform price auctions. However, ecological efficiency might not be reached when procurement from the lowest bidders delivers a fragmented outcome and crucial pathways to connect different habitat patches are not formed (Margules and Pressey 2000, Williams and Snyder 2005, Conrad et al. 2012). ${ }^{1}$ Mechanisms in which the payment received for conserving a plot depends on the number of retired neighboring plots (so-called agglomeration bonuses) can help reduce this potential fragmentation problem (Parkhurst et al. 2002, Parkhurst and Shogren 2007, Wätzold and Drechsler 2005, Drechsler et al. 2010). ${ }^{2}$

Experimental studies on the effectiveness and efficiency of agglomeration bonuses typically use fixed corridor values and opportunity costs, and they also impose that participation is mandatory ( $c f$. Parkhurst and Shogren 2008). These assumptions are often violated in the real world, where typically not all eligible landowners submit bids. Many factors may cause landowners to refrain from submitting a bid, but one of them may be strategic considerations. For instance, if a landowner has a strategic position in the landscape (e.g. if her land is located in the middle of an obvious corridor), she may have an incentive to submit a very high bid in the auction, or even holdout completely - for example if she expects to get a higher price outside of the auction. The results from experimental workshops with landowners in Australia also suggest to design corridor auctions including agglomeration bonuses, and to have as many potential corridors bidding for a contract as possible to reduce the potential of these kind of 'holdout bids' (Windle et al. 2005). ${ }^{3}$

In this paper, we introduce a corridor auction model in which we test the market performance of the agglomeration bonus and compare it with a strategic buyout. The latter entails the purchase of a strategic plot in the landscape prior to the auction, resulting in the landowner with the highest potential for holdout bids not participating in the auction. ${ }^{4}$ Given (i) some spatial configuration of landowners in a landscape, (ii) the landowners' opportunity costs, and (iii) the value of establishing the corridor, our model predicts individual landowners' bids, overall participation rates in the auction, as well as the expected net benefits to the conservation agency for both mechanisms.

The model indicates that a corridor auction features less competition between coalitions of landowners than an identical spatial auction - i.e. one that does not necessitate the formation of a corridor. Hence, (coalitions of) landowners expect higher profits when deciding to join a corridor auction - a result that is echoed in the simulation study of Iftekhar and Tisdell (2016). However, our model also shows that there is a tradeoff between (1) higher participation rates of individual landowners due to these higher expected profits in corridor

\footnotetext{
${ }^{1}$ The biodiversity losses of habitat fragmentation are substantial. In a 35-year survey of fragmentation experiments on five continents, Haddad et al. (2015) find that fragmented habitat reduces the diversity of plants and animals by 13 to 75 percent, with the largest biodiversity losses found in the smallest and most isolated fragments of habitat.

2 Typically, an agglomeration bonus is shown to be cost-effective when the benefits of reduced fragmentation outweigh the costs of offering the bonus to groups of landowners that have common borders ( $c f$. Parkhurst et al. 2002). The latter is a rather artificial result as, for instance in an experimental setting, one can simply assume that the benefits of connecting conservation areas are so high that reducing fragmentation with a certain bonus is always beneficial.

${ }^{3}$ See Sarkar (2016) for a formal model in which certain sellers play a critical role in the success of a market mechanism due to the nature of their connections with other sellers.

${ }^{4} \mathrm{We}$ assume that the landowner with the highest potential for holdout bids (i.e. the most connected landowner in the landscape or the socalled 'pivotal landowner') does not participate because the buyout occurs prior to performing the corridor auction (see Section 3 for details). This player always receives the highest possible payment (which is equal to the highest possible bid in the corridor auction he/she would otherwise participate in and can even be higher; see Section 4).
} 
auctions, and (2) a lower number of possible winning coalitions an individual landowner can be part of due to the requirement that winning coalitions form a viable corridor. The net results of these two forces on market efficiency of the corridor auction depend on the three features of the landscape that are given above.

The main result of our corridor auction simulations for a symmetrical $3 \times 3$ landscape is that a strategic buyout policy may outperform an agglomeration bonus. The simulations show that strategic buyouts increase participation rates, and if participation rates are expected to be low, the increased competition (and the resulting decrease in bids) induced by strategic buyouts can reduce the overall costs incurred by the conservation agency. However, if participation rates are expected to be high in the corridor auction, the conservation agency is better off without strategic buyouts. Furthermore, for sufficiently generous agglomeration bonuses, we find that the bonus is more efficient than a strategic buyout. Nevertheless, a conservation agency that wishes to avoid the risk of very costly procurement is better off using the buyout policy. The reason is that the buyout simulations feature a narrower range of procurement costs. Hence, although the average winning coalition bids are lower in the corridor auction with the agglomeration bonus, opting for the strategic buyout before the auction takes place reduces the risk that the corridor has to be procured at a very high cost.

In this paper, we argue that whether or not participation is voluntary, is a crucial factor affecting the efficiency of spatial procurement auctions. Research on the design and procurement of optimal contiguous habitat typically does not include voluntary participation, but features a conservation planner who aims to minimize the costs of (for instance) the procurement of a wildlife corridor. Hence, it is implicitly assumed that the conservation planner has full information on the (opportunity) costs of procuring land from different landowners, and that all landowners will participate (cf. Ando et al. 1998, Williams 1998, Williams and Snyder 2005, Conrad et al. 2012). Bamière et al. (2013) do assume asymmetric information with respect to the landowners' opportunity costs, but they do not allow for voluntary participation in their auction model. ${ }^{5}$ Furthermore, they assume that bids are sealed and that landowners do not collude. However, in networked industries such as farming, bids are expected to spread quickly through the local farmer community (LataczLohmann and van der Hamsfoort, 1998, Latacz-Lohmann and Schilizzi, 2005). Note that in our model, after deciding whether to participate, landowners are also assumed not to collude (i.e. simultaneously increase their bids to improve their gains). However, we do assume that the bids of the individual landowners are derived from the optimal coalition bids of landowners who can form potential corridors (which in turn are based on the coalitions' opportunity costs). We believe this to be a far more realistic assumption than that of no collusion in auctions for contiguous habitat, or wildlife corridor auctions specifically. ${ }^{6}$

Participation rates in procurement auctions are typically low (cf. Brown et al. 2011, Bartolini et al. 2013, DePiper et al. 2013), and our model shows that restricting a spatial auction by necessitating the procurement of a corridor is expected to decrease participation rates even more. Our results show that designing an effective agglomeration bonus or determining the characteristics of a successful buyout policy can be important tools in increasing the market efficiency of these auctions. In the remainder of this paper, we demonstrate this result and provide conditions under which one mechanism is preferable to the other.

\footnotetext{
${ }^{5}$ Conversely, Parkhurst et al. (2016) allow voluntary participation in their experimental setting, but they assume that the conservation planner has full information.

${ }^{6}$ See Krawczyk et al. (2016) for an experimental study on the effect of coordination (via chat) in an experimental setting. They find that coordination has a neutral effect on social welfare in their experimental design. It encourages collusion, leading to higher prices and lower social welfare, but it also increases welfare as coordination facilitates the construction of longer corridors.
} 


\section{A corridor auction model}

We consider a spatial configuration of landowners $i \in N$, who each own one plot of land and who differ in terms of the location of their land as well as in their opportunity costs of providing conservation, $c_{i}>0$. A conservation agency intends to contract (or buy) land such that a corridor is formed between two existing nature conservation areas. We consider the non-trivial case where there are multiple coalitions of landowners that can form such a corridor. We will focus our analysis on what we call viable corridors. Denote a coalition that provides a viable corridor (i.e. a viable coalition) by $S \subseteq N$. Viable corridors (i) connect the two conservation areas, and (ii) are efficient in the sense that no redundant players are included. For instance, if a coalition of three landowners $S=\{1,2,3\}$ forms a viable corridor, the larger coalition $S^{\prime}=\{1,2,3,4\}$ is not viable. The number of viable corridors in the landscape is given by $n$, the level of which depends on assumptions with respect to connectivity of plots of land. The model allows for all sorts of connectivity assumptions, but in the simulations in the following sections we assume queen contiguity, that is, we allow for both horizontal and diagonal connections ( $c f$. Parkhurst et al. 2002, Drechsler et al. 2010, Iftekhar and Tisdell 2014).

The conservation agency maximizes its net benefits by choosing the cheapest viable corridor $S^{*}$, based on coalition bids $B_{S}=\sum_{i \in S} b_{i}$ (defined as the sum of individual landholders' bids $b_{i}$ for each corridor $S$ ):

$$
\mathrm{S}^{*}=\arg \max _{\mathrm{S}} V-B_{S}
$$

where the net benefit is the difference between the value of the viable corridor $V$, which we assume fixed, ${ }^{7}$ and the lowest coalition bid $B_{S}$. To ensure that net benefits are always nonnegative, we assume that the conservation agency announces an upper bound $\bar{b}$ on individual bids. Using \#S to denote the number of landowners in $S,{ }^{8} \bar{b}$ is set such that $V \geq \max \{\# S \bar{b}\}$ (i.e. $V \geq B_{S}$ for all $S$ ). To avoid the integral notation that comes with continuous bidding ( $c f$. Cason 1993), we assume that individual landowners can only submit bids in integers in the range of $[1, \bar{b}]$; a bid equal to zero is thus not accepted. ${ }^{9}$ We also assume that landowners are risk neutral.

We take a five-step approach to solve for the optimal individual bids. First, we solve for the profitmaximizing coalition bids of all viable coalitions. Second, we calculate the expected individual profits based on the marginal contributions of landowners to the optimal coalition bids, using a modified version of the Shapley value (Roth 1988, Jackson 2005, Macho-Stadler et al. 2007). Third, based on expected individual profits, we determine which landowners will participate in the auction. Fourth, we repeat the first step based on the updated number of participants in the auction. Fifth, we determine individual landowners' bids based on the updated coalition bids.

\footnotetext{
${ }^{7}$ Denoting the value of the corridor by $V$ simplifies the interpretation of the theoretical results. Note that differences in opportunity costs $c_{i}$ account for spatial heterogeneity in our model. Adding the assumption that some corridors are more valuable than others would unnecessarily complicate our analysis, but is an obvious candidate for a possible extension ( $c f$. Williams et al. 2012 for further discussion on how and why corridor values should differ).

${ }^{8}$ For example, for $S=\{1,5,7\}$ we denote the coalition size by $\# S=3$.

${ }^{9}$ Limiting the number of digits is not uncommon in practice and actually recommended to reduce the possibilities to signal in open-bid auctions (see Cramton and Schwartz 2000).
} 
Step I: Solve for the coalition bids of all viable coalitions.

Each viable coalition solves the following profit maximization problem, where $E(\bullet)$ denotes expectations, $\operatorname{Pr}(\bullet$ ) denotes probability, and with $C_{S}=\sum_{i \in S} C_{i}$ :

$$
\begin{aligned}
B_{S}^{*}=\arg \max _{B_{S}} E\left(\pi_{S}\right) & =\left(B_{S}-C_{S}\right) \operatorname{Pr}\left(\left(V-B_{S}\right) \geq\left(V-B_{U}\right)\right) \forall U \neq S \\
& =\left(B_{S}-C_{S}\right) \operatorname{Pr}\left(B_{S} \leq B_{U}\right) \forall U \neq S .
\end{aligned}
$$

To make $\operatorname{Pr}\left(B_{S} \leq B_{U}\right)$ explicit, we follow Cason (1993) and make use of the $k$ th order statistic (recall that we assumed risk neutral landholders who can only make integer bids):

$$
\begin{aligned}
B_{S}^{*}=\arg \max _{B_{S}} E\left(\pi_{S}\right) & =\left(B_{S}-C_{S}\right) \frac{\sum_{k=0}^{n-1}\left[\frac{(n-1) !}{(n-k) ! k !}\left(V-B_{S}\right)^{k}\right]}{V^{n-1}} \\
& =\left(B_{S}-C_{S}\right) \frac{\left(\mathrm{V}-B_{S}+1\right)^{n}-\left(\mathrm{V}-B_{S}\right)^{n}}{n V^{n-1}} .
\end{aligned}
$$

The FOC of the maximization problem in (3) can be written as

$$
\frac{(n+1) B_{S}^{*}-n C_{S}-V-1}{(n+1) B_{S}^{*}-n C_{S}-V}=\left(\frac{\mathrm{V}-B_{S}^{*}}{\mathrm{~V}-B_{S}^{*}+1}\right)^{n-1}
$$

The RHS of this FOC is positive for any $n$ and any $B_{S}^{*}<V .{ }^{10}$ Therefore, the LHS should be positive too, which implies that $(n+1) B_{S}^{*}-n C_{S}-V-1>0$, or, equivalently, $B_{S}^{*}>\left(n C_{S}+V+1\right) /(n+1)$. This condition is employed in the simulations in Section 3.

To illustrate (4), for $n=2$ and $n=3$ the profit maximizing coalition bids are:

$$
\begin{gathered}
B_{S, n=2}^{*}=\frac{1}{2}\left(C_{S}+V\right)+\frac{1}{4} \\
B_{S, n=3}^{*}=\frac{1}{3}\left[1+C_{S}+2 V-\sqrt{\left(V-C_{S}+1\right)\left(V-C_{S}\right)}\right] .
\end{gathered}
$$

Analytical solutions are not possible for higher values of $n$, but see Proposition 1 below.

\footnotetext{
${ }^{10}$ The value of the corridor $(V)$ shows up in (3) and (4) due to our assumption that the net benefits of the corridor auction are always nonnegative: $V \geq \max \{\# S \bar{b}\}$, i.e. $V \geq B_{S}$ for all $S$. Hence, $V=\max \{\# S \bar{b}\}$ can be substituted in (3)-(7) and (10), but we chose to use $V$ to keep notation simple. Solving for the optimal landowner/coalition bids thus does not require landowners to have information on the value of $V$, but we do assume that landowners know that there exists an upper bound $\bar{b}$ on individual bids (to be able to solve the model analytically). This assumption can for instance be relaxed by allowing for uncertainty on the maximum bid that is accepted, or $V=E(\max \{\# S \bar{b}\})$ in $(3)$ (7) and (10). Note that as long as $E(\max \{\# S \bar{b}\})$ is the same for all landowners, the optimal bids can still be calculated using the model that is presented here.
} 
Step II: Calculate the expected individual profits.

If a coalition $S$ wins, each member of this coalition $i \in S$ receives his bid $b_{i}$, as determined below, which is not corridor-specific. ${ }^{11}$ Given Equation (4) and a value for $n$ (the latter being a value that a conservation agency will have at its disposal prior to the auction assuming that all potential corridors have been determined and communicated to the bidders on forehand) we can use the optimal coalition bids from Step I as inputs to solve for the expected profits of each individual landowner, or $E\left(\pi_{i}\right)$. These expected individual profits can be calculated using the probability formulation from (2) and (3) which yields:

$$
\begin{aligned}
& E\left(\pi_{i}\right)=\left(b_{i}-c_{i}\right) \sum_{S: i \in S} \operatorname{Pr}\left(B_{S}^{*} \leq B_{U}^{*}\right) \forall U \neq S \\
& =\left(b_{i}-c_{i}\right) \sum_{S: i \in S}\left[\frac{\left(\mathrm{V}-B_{S}^{*}+1\right)^{n}-\left(\mathrm{V}-B_{S}^{*}\right)^{n}}{n V^{n-1}}\right] .
\end{aligned}
$$

The sum on the RHS in (7) adds up the probabilities of winning the auction for all coalitions $S$ that landowner $i$ is part of. Individual agents' bids $b_{i}$ are then calculated using the Shapley value, as follows.

Using the Shapley value requires determining each landowner's marginal contribution to the different viable coalitions that he belongs to. The probabilistic interpretation of the Shapley value is that agents enter a room one by one in some order and each agent receives the marginal contribution created by him. Landowner $i$ 's Shapley value is then calculated as his average contribution to the game, which equals his average marginal contribution over all possible orderings of landowners. For $i \in S$, and $v(S)$ indicating the worth of coalition $S$ (to the landowner), the Shapley value can be written as

$$
b_{i}=\sum_{S: i \in S}\left[\frac{(\# S-1) !(n-\# S)}{n !}\right] \cdot[v(S)-v(S \backslash i)] .
$$

This formulation can be simplified in several ways because of the specifics of the corridor auction. Note that in this auction, for any ordering of landowners, there is only one landowner that generates a positive marginal contribution to a coalition $S \subseteq N$. It is the landowner that 'finishes' some viable corridor who receives the full value of the corridor as his marginal contribution. ${ }^{12}$ Hence, we can focus the calculation of the Shapley value to viable coalitions $S$ only, since calculations for all nonviable coalitions yield zero allocations to the other landowners. Furthermore, it is natural to assume that each coalition $S$ has an equal probability of being formed,

\footnotetext{
${ }^{11}$ We differ from Iftekhar and Tisdell (2014) in that we do not allow for corridor-specific bids by the landowners. These would potentially allow landowners to inflate coalition bids on one corridor to increase windfall profits on another corridor (for which they believe their bid is competitive). Iftekhar and Tisdell's results show that bids are indeed higher when corridor-specific bids are allowed. They proceed to argue against the use of corridor-specific bids and the related option of corridor-specific participation decisions, not only because of potentially higher windfall profits, but also because it may obstruct the formation of viable corridors. Note that we also ignore the possibility of side payments - the bid $b_{i}$ thus corresponds to the full revenue that an individual landowner can receive by being part of the winning coalition. ${ }_{12}$ For instance, consider a viable corridor that can be established by a coalition of 3 landowners: $S=\{1,2,3\}$. Assume that landowner 1 starts the coalition and is joined by landowner 2 and 3 (in that order). In this case, landowners 1 and 2 have a marginal contribution of zero, and landowner 3 has a marginal contribution of $B_{S}$. In this case, there are $\# S !=3 !=6$ possible orderings in which landowners can join (or start) a coalition. Given that the corridor only has value if all 3 landowners are in the coalition, only when an individual joins as the third member will its marginal contribution be non-zero, e.g. for landowner 1 these are ordering $\{2,3,1\}$ and $\{3,2,1\}$, or: $(\# S-1) !=(3-1) !=2$. The value of this particular corridor for landowner 1 is thus equal to $[(\# S-1) ! / \# S !] B_{S}=[1 / \# S] B_{S}=\frac{1}{3} B_{S}$ and should be added to the marginal contributions a landowner has in other viable corridors, if any.
} 
and that each landowner $i \in S$ has an equal probability of being the last one that finishes the viable corridor.

Based on these observations, we can simplify (8) to

$$
b_{i}=\left(\frac{1}{m_{i}}\right) \sum_{S: i \in S}\left[\frac{B_{S}^{*}}{\# S}\right]
$$

where $m_{i}$ denotes the number of viable coalitions $S$ that include landowner $i$ and \#S denotes the number of landowners in every viable coalition $S$ that landowner $i$ belongs to. The Shapley value calculation in (9) states that each individual landowner's bid is simply based on equal shares of the value (i.e. the coalition bid) of each of the viable corridors that he is a member of. ${ }^{13}$ Combining (7) and (9) we obtain

$$
E\left(\pi_{i}\right)=\left(\left(\frac{1}{m_{i}}\right) \sum_{S: i \in S}\left[\frac{B_{S}^{*}}{\# S}\right]-c_{i}\right) \sum_{S: i \in S}\left[\frac{\left(\mathrm{V}-B_{S}^{*}+1\right)^{n}-\left(\mathrm{V}-B_{S}^{*}\right)^{n}}{n V^{n-1}}\right]
$$

Step III: Determine the landowners' participation decisions.

The individual landowners' participation decisions now simply entail the participation decision rule $E\left(\pi_{i}\right) \geq 0$ as given by (10). In words, we assume that an individual landowner will decide to participate in the auction if and only if his expected profits in the auction are larger than or equal to zero. Note here that (10) offers the formal participation decision, but since it always holds that $\sum_{S: i \in S} \operatorname{Pr}\left(B_{S}^{*} \leq B_{U}^{*}\right) \geq 0$ in (7), it is sufficient to check whether $b_{i}-c_{i} \geq 0$ holds, with $b_{i}$ given by (9).

\section{Step IV: Recalculate the profit maximizing coalition bids.}

This step basically is a reiteration of Step I given the landowners' participation decisions in Step III. These decisions reduce the number of participants in the auction and thereby reduces the number of viable corridors from $n$ to $n^{\prime} \leq n$. For this new number of corridors, we use the FOC in (4) to update the optimal coalition bids from $B_{S}^{*}$ to $B_{S^{\prime}}^{*}$. This procedure could be iterated more often, including Steps II and III, if desired. ${ }^{14}$

\footnotetext{
13 The modified Shapley value in (9) allows the number of individual landowners that constitutes a viable coalition (\#S) to be higher than the number of potential corridors an individual landowner can join $\left(m_{i}\right)$. This is not a standard feature of cooperative games; it is induced by the participation decision in our model. Note that applying our modified version of the Shapley value delivers identical results to the hypothetical landscape described by Iftekhar and Tisdell (2014), who ignored this feature, but only because their landscape has $\# S=3<$ $m_{i}=4$ for all agents.

${ }^{14}$ Repeated iteration may lead to increasing or decreasing participation rates over the iterations, depending on the outcome of two forces. Consider some landowners dropping out in the initial participation decision. One force is that reduced participation implies fewer possible corridors and by the proposition below, higher coalition bids, which would lead to higher expected profits and thereby increased participation in the next iteration. The other force, however, is that reduced participation may prevent the formation of certain viable corridors. They drop out. In case corridors with a high bid drop out, this would lead to lower expected profits and thereby decreased participation in the next iteration. The combined effect of these two forces is not clear and simulations show that both are possible. The choice to model only one iteration may seem arbitrary, but the obvious alternative - repeated iteration until participation is stable - gives rise to the problem of choosing the correct equilibrium selection rule. We avoid this by assuming that landowners have limited mathematical induction capabilities in determining their participation decisions (cf. Johnson et al. 2002, Camerer and Johnson 2004).
} 
Step V: Calculate the individual landowners' (updated) bids.

Using $B_{S^{\prime}}^{*}$ (i.e. the updated coalition bids), individual landowners' bids are calculated using the modified version of the Shapley value, as introduced in Step II. We obtain

$$
b_{i}^{\prime}=\left(\frac{1}{m_{i}^{\prime}}\right) \sum_{S^{\prime}: i \in S^{\prime}}\left[\frac{B_{S^{\prime}}^{*}}{\# S^{\prime}}\right] .
$$

Similar to the notation used in Step II, in the RHS fraction, $m_{i}^{\prime}$ now denotes the number of viable coalitions $S^{\prime}$ that include landowner $i$. The individual landowners' bids $b_{i}^{\prime}$ are the updated versions of $b_{i}$ after the landowners' participation decisions in Step III and the recalculations in Step IV have been accounted for. Not only does this auction select the corridor with the highest net benefit, the auction as described above also selects the cheapest corridor to connect the two existing conservation areas. This is because $B_{S^{\prime}}^{*}$ is strictly decreasing in $C_{S^{\prime}}$.

Having solved for the optimal individual bids we proceed with the proposition below which states that, as the number of viable corridors $n$ increases, competition between coalitions increases and the profit maximizing coalition bids decrease. This result is used in the next section to explain the functioning of the agglomeration bonus and the buyout policy.

Proposition 1: For any $V-B_{S}^{*}>0$ and $n \geq 2$, we have that $B_{S}^{*}$ is decreasing in $n$, i.e. $\frac{d B_{S}^{*}}{d n}<0$.

\section{Proof: See Appendix A.}

The proposition holds for any $V-B_{S}^{*}>0$. Note, though, that if $V-B_{S}^{*}=0$ the condition that $V \geq \max \{\# S \bar{b}\}$

(i.e. $V \geq B_{S}$ for all $S$ ), prevents $\frac{d B_{S}^{*}}{d n}>0$ by construction, see (3). In the simulations in Section 4, we will therefore allow for $B_{S}^{*}=V$.

As an example of our auction model, consider the hypothetical landscape in Figure 1. The conservation agency wishes to establish a wildlife corridor between conservation areas A and B by contracting with a subset of the eight landowners. There are $n=8$ viable corridors and we assume $V=50$. Opportunity costs (see Table 1) are selected such that higher opportunity costs are attributed to landowners who own a larger patch of land and are closer to the body of water, which is depicted as the shaded area in the middle of Figure 1. Table 1 offers a summary of parameter values at the level of viable coalitions (coalition $S$, coalition size $\# S$, and opportunity costs $C_{S}$ ), and at the level of individual landowners (opportunity costs $c_{i}$, and number of viable coalitions $n_{i}$ that include $i$ ). Given these parameter values, we determine the profit maximizing individual bids and coalition bids, both before $\left(b_{i}\right.$ and $\left.B_{S}^{*}\right)$ and after $\left(b_{i}^{\prime}\right.$ and $\left.B_{S^{\prime}}^{*}\right)$ the participation decision, as well as $n_{i}^{\prime}$, the updated number of viable corridors that include $i$. 
Figure 1. A hypothetical landscape with eight landowners.

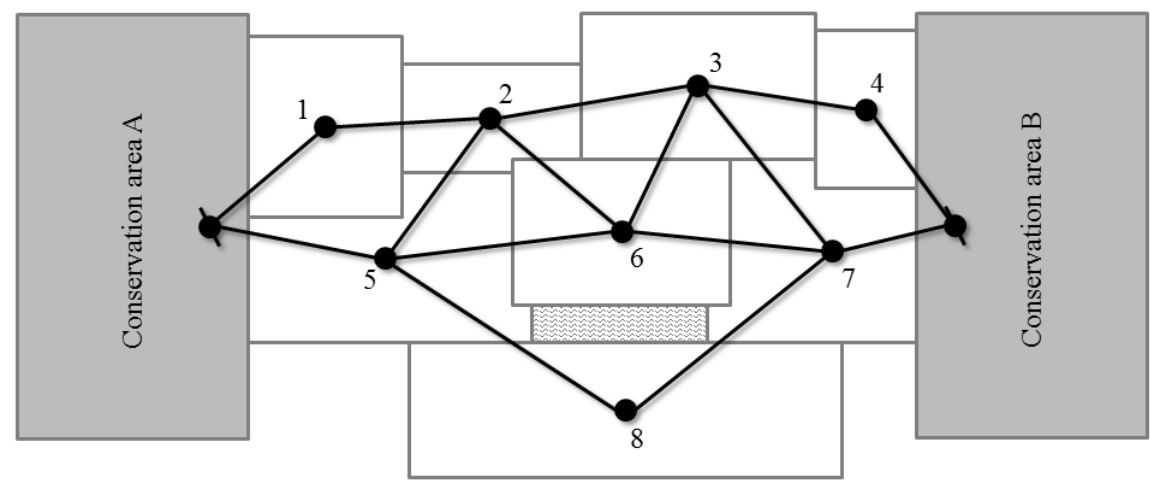

Since landowners will only participate if $E\left(\pi_{i}\right) \geq 0$, which we know implies $b_{i}-c_{i} \geq 0$, we find that landowners 5, 6 and 8 decide not to participate, leaving $n^{\prime}=2$ potential corridors: $\{1,2,3,4\}$ and $\{1,2,3,7\}$. Using this information to recalculate the profit maximizing coalition bids and the landowners' individual bids in (10) and (11), we find that the conservation agency will procure corridor $\{1,2,3,4\}$ for a price of $B_{S^{\prime}}^{*}=34$, and that landowners $1,2,3$ and 4 make windfall profits $\left(b_{i}^{\prime}-c_{i}\right)$ of $4,3,1$ and 6 , respectively.

Table 1. Numerical example based on the landscape of Figure 1.

\begin{tabular}{|c|c|c|c|c|}
\hline$\{$ Corridor $\}(S)$ & $\# S$ & $C_{S}$ & $B_{S}^{*}$ & $B_{S^{\prime}}^{*}$ \\
\hline (21,2,3,4\}(1) & 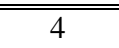 & 18 & 22 & 34 \\
\hline$\{1,2,3,7\}(2)$ & 4 & 24 & 27 & 37 \\
\hline$\{1,2,6,7\}(3)$ & 4 & 26 & 29 & - \\
\hline$\{5,2,3,4\}(4)$ & 4 & 26 & 29 & - \\
\hline$\{5,2,3,7\}(5)$ & 4 & 32 & 34 & - \\
\hline$\{5,6,3,4\}(6)$ & 4 & 30 & 32 & - \\
\hline$\{5,6,7\} \quad(7)$ & 3 & 29 & 31 & - \\
\hline$\{5,8,7\} \quad(8)$ & 3 & 35 & 36 & - \\
\hline Landowner $(i)$ & $n_{i}\left(n_{i}^{\prime}\right)$ & $c_{i}$ & $b_{i}$ & $b_{i}^{\prime}$ \\
\hline 1 & $3(2)$ & 4 & 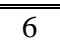 & 8 \\
\hline 2 & $5(2)$ & 5 & 7 & 8 \\
\hline 3 & $5(2)$ & 7 & 7 & 8 \\
\hline 4 & $3(1)$ & 2 & 6 & 8 \\
\hline 5 & $5(-)$ & 12 & 9 & - \\
\hline 6 & $3(-)$ & 9 & 8 & - \\
\hline 7 & $5(1)$ & 8 & 8 & 9 \\
\hline 8 & $1(-)$ & 15 & 12 & - \\
\hline
\end{tabular}

The example of Figure 1 confirms Proposition 1 by demonstrating that participation decisions have severe consequences on the net benefit of realizing the corridor (compare columns $b_{i}$ and $b_{i}^{\prime}$ of Table 1). Also, Table 1 shows that landowners can obtain large windfall profits even if a few landowners decide not to participate. In the next section, we will describe the simulation framework that is used to test our auction model as well as additional policy scenarios that can be used to increase participation rates, and thereby increase the market efficiency of the auction. 


\section{Simulation framework and scenarios}

The simulation framework that we use is based on the symmetrical landscape (a $3 \times 3$ grid) displayed in Figure 2. The conservation agency wishes to establish a wildlife corridor between conservation areas A and B by contracting with a subset of the nine landowners. As before, we allow for horizontal and diagonal connections and viability implies that we only consider coalitions in which one landowner per column is selected. This leaves us with $3 \times 3 \times 3=27$ possible coalitions of 3 landowners. By the definition of viable coalitions, 17 coalitions are viable (e.g. $\{1,5,6\})$ and 10 are not (e.g. $\{4,2,9\})$. Figures 7 and 8 in Appendix B offer a detailed description of the viable corridors and the number of coalitions that individual landowners can join in this landscape.

Figure 2. Landscape based on a $3 \times 3$ grid used in the auction simulations.

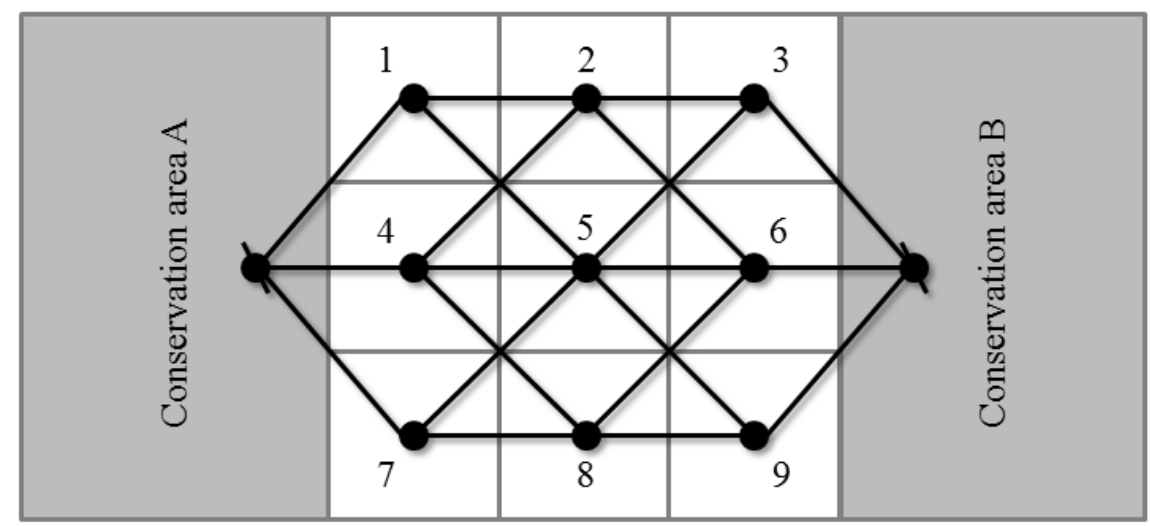

We consider four main scenarios: the spatial auction (SA), the corridor auction (CA), the agglomeration bonus $(\mathrm{AB})$, and the buyout (BO) scenario. In the spatial auction scenario and corridor auction scenario, landowners submit bids in the auction as described in Section 2. Hence, the nine landowners of Figure 2 submit individual bids that determine the coalition bids for all possible coalitions in this landscape (or less if some decide not to participate). These two scenarios only differ in the number of corridors that are considered. SA has 27 possible winning coalitions (i.e. groups of three landowners) while CA only includes the 17 viable coalitions that constitute corridors (see Figure 7). Hence, any difference in the simulation results between these two scenarios will be driven by the difference in $n$, the number of coalitions.

By Proposition 1, increased participation will increase market efficiency of the auction. There are many mechanisms to increase participation rates and we consider two of these. In the agglomeration bonus scenario, we increase the expected profits of joining the auction for all landowners with a so-called agglomeration bonus. In this scenario, the winning coalition receives an extra payment on top of their aggregate bid, which is equally divided between the coalition members. In the buyout scenario, we assume that the conservation agency buys out pivotal landowner 5 prior to the auction - thereby increasing the probability of winning for the six remaining bidders (landowners 1, 3, 4, 6, 7 and 9) but also reducing the total number of viable corridors from $n$ $=17$ to $n=9$.

The BO scenario requires four assumptions. First, we assume that the conservation agency has imperfect information about the opportunity costs of the landowners, but does know that these opportunity costs are 
restricted to a certain range: $c_{i} \in[\underline{c}, \bar{c}] .{ }^{15}$ Second, we assume that the conservation agency buys out only one landowner - the pivotal landowner. Since the agency has imperfect information about the opportunity costs, pivotal landowners are determined only by their connectedness in the landscape. In our landscape, landowner 5 is the pivotal landowner since he is part of 9 potential viable corridors, while landowners 2 and 8 are the least pivotal given that they are part of only 4 potential viable corridors (see Figure 8 ). ${ }^{16}$ Third, we assume that the winning corridor will always include the purchased plot of landowner 5, so that landowners 2 and 8 cannot participate in the auction. Fourth, since the conservation agency does not know the opportunity cost of landowner 5, the buyout compensation is set equal to $\beta=\bar{c}$, to ensure that the landowner makes a profit (or at least breaks even). ${ }^{17}$ To ensure a fair comparison of $\mathrm{BO}$ with $\mathrm{AB}$, the agglomeration bonus in the $\mathrm{AB}$ scenario is set equal to $\beta=\bar{c}$. Again, we assume that this bonus is added to the aggregate bid of the winning coalition and is equally divided between the members of this coalition.

In order to assess the effects of the level of $\beta$ on the relative performance of $\mathrm{AB}$ and $\mathrm{BO}$, we include two additional variants of the agglomeration bonus (AB2) and buyout (BO2) scenarios, in which we simply multiply the bonus and buyout compensation by 2 , i.e. $\beta=2 \bar{c}$ in these scenarios. Note that in $\mathrm{BO} 2$, windfall profits of landowner 5 are increased compared to $\mathrm{BO}$, but otherwise bidding behavior does not change - i.e. the participation decisions of the remaining landowners in auction are unaffected by the size of the buyout compensation. In AB2, however, bidding behavior may change due to the effect on the participation decisions (see Proposition 1).

By Proposition 1, we expect windfall profits to be lower in the (less restricted) SA than in the CA, due to the number of possible coalitions being higher in the SA than in the CA, which induces more competition and thus should increase market efficiency. However, increased market efficiency implies lower expected profits, so participation rates of individual landowners are expected to be lower in the SA than in the CA. Hence, there is a tradeoff between (i) lower participation rates of individual landowners due to lower expected profits in the SA, and (ii) a higher number of possible coalitions an individual landowner can be part of in the SA (even when participation rates are lower). The result of these two forces on market efficiency is unclear and will depend on the parameter values of the simulations, i.e. the value of the corridor $V$ and the selected range of opportunity costs $c_{i} \in[\underline{c}, \bar{c}]$.

With respect to the policy scenarios, we predict that $\mathrm{AB}$ and $\mathrm{BO}$ improve participation rates compared to the benchmark CA. Because these 3 scenarios feature the same initial number of viable corridors $n=17$, this increased participation rate implies higher market efficiency in $\mathrm{AB}$ and $\mathrm{BO}$ compared to the $\mathrm{CA}$ scenario. In the $\mathrm{AB}$ scenario, $\beta$ has a positive effect on expected profits and thereby on participation (and competition). In the BO scenario, the buyout stimulates participation (and competition) if landowner 5 would otherwise not participate, i.e. when the opportunity costs for landowner 5 are relatively high compared to those of the other landowners. In this case, the buyout will stimulate competition at a location in the landscape where many viable pathways can be created, but would otherwise not be feasible to procure by the conservation agency. Obviously, the reverse argument holds when landowner 5 would also participate without the buyout. We thus expect the relative performance of the $\mathrm{AB}$ and the $\mathrm{BO}$ scenarios to depend on the parameter values of the simulations.

\footnotetext{
${ }^{15}$ Note that Bamière et al. (2013) make a similar assumption in their auction model.

${ }^{16}$ Note that the landscape in Figure 2 is conducive for good performance of the buyout scenarios (described below). In other landscapes, say larger ones or landscapes without a clear pivotal landowner, the buyout of just one landowner may result in low market efficiency of the buyout policy.

${ }^{17}$ We assume that the buyout is mandatory here, but see Section 4 for a discussion on employing a so-called 'voluntary buyout'
} 


\section{Simulation results}

Our simulations are based on the auction model presented in Section 2 and the scenarios described in Section 3. The auction simulations are performed in Wolfram Mathematica. ${ }^{18}$ For every scenario in Section 3 , the auction results are based on random draws of opportunity costs for the nine individual landowners assuming that the corridor value is low $(V=40)$, medium $(V=70)$ or high $(V=100)$, and the range of opportunity costs is either narrow $\left(c_{i} \in[3,8]\right)$ or wide $\left(c_{i} \in[1,10]\right){ }^{19}$ The opportunity costs are in integers and are (pseudo-)randomly ${ }^{20}$ drawn from a uniform distribution. For each scenario in Section 3, and for each possible combination of corridor value $V$ and range of opportunity $\operatorname{costs} c_{i}$, the simulation results are based on 10,000 observations for groups of 9 individual landowners with random opportunity costs in every run. Hence, in Figures 3, 4, 5 and 6, each observation represents an average (or distribution) of 10,000 observations of auctioning (based on 10,000 strings of 9 randomly drawn opportunity costs). ${ }^{21}$ Detailed simulation results are offered in an online Appendix (Tables 2 and 3). ${ }^{22}$ The main results are presented below.

Figure 3. Average winning coalition bids.

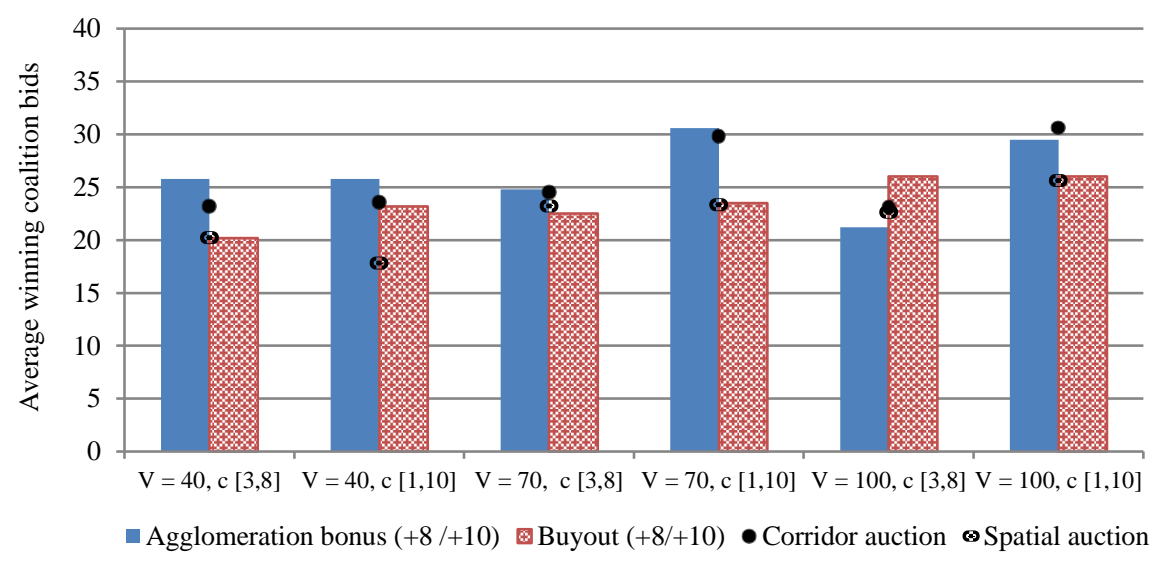

Note that the agglomeration bonus/buyout compensation is added to the winning coalition bid to ease comparison. The size of the bonus or the compensation is either equal to 8 or 10 depending on the opportunity cost range that applies.

First, consider the average winning coalition bid in Figure $3\left(B_{S^{\prime}}^{*}\right.$ for the coalition with the lowest bid) and the participation rates of the individual landowners in Figure 4. Note that in $A B(B O)$ the size of the bonus (buyout compensation) is either equal to 8 or 10 dependent on the relevant opportunity cost range. Results of the four main scenarios are grouped for six corridor value/cost range combinations. ${ }^{23} \mathrm{We}$ find that the average winning coalition bid is always significantly lower in SA than in CA. Furthermore, the average participation

\footnotetext{
${ }^{18}$ The simulation code is available upon request.

${ }^{19}$ Other values have been tested, but with the current value ranges we believe we sufficiently capture possible differences in efficiency between scenarios. Note that although the range of opportunity costs is different, the means are the same.

${ }^{20}$ From the Mathematica Documentation: "The sequences that you get [...] are not in most senses "truly random", although they should be "random enough" for practical purposes. The sequences are in fact produced by applying a definite mathematical algorithm, starting from a particular "seed". [...] When the Wolfram Language starts up, it takes the time of day (measured in small fractions of a second) as the seed for the pseudorandom number generator. Two different Wolfram Language sessions will therefore almost always give different sequences of pseudorandom numbers."

${ }^{21}$ The exception being the six columns for the BO2 scenario in Figure 5, and the distribution of BO2 in Figure 6. Since moving from BO to $\mathrm{BO} 2$ only causes windfall profits to increase for landowner 5 , the doubled compensations $(\beta=2 \bar{c})$ were simply added to the results of the BO scenarios instead of the normal compensation $(\beta=\bar{c})$.

${ }^{22}$ The online Appendix is available at [ADD LINK HERE].

${ }^{23}$ We refer to coalition values instead of corridor values for the SA scenario.
} 
rate in $\mathrm{CA}$ is always significantly higher than in SA. ${ }^{24}$ It appears that for this particular landscape, lower participation rates of the individual landowners have less of an impact on competition in SA than in CA. Even though there are fewer individual landowners that participate in SA than in CA, the 'extra' coalitions in SA (see Figure 7 in the online Appendix) result in more competition among coalitions. Note that we cannot exclude that in a landscape with a smaller difference between the numbers of competing coalitions for these two scenarios the results will be reversed. However, for this particular landscape, the requirement of a viable corridor in the CA scenario has a negative effect on market efficiency.

Figure 4. Average participation rates.

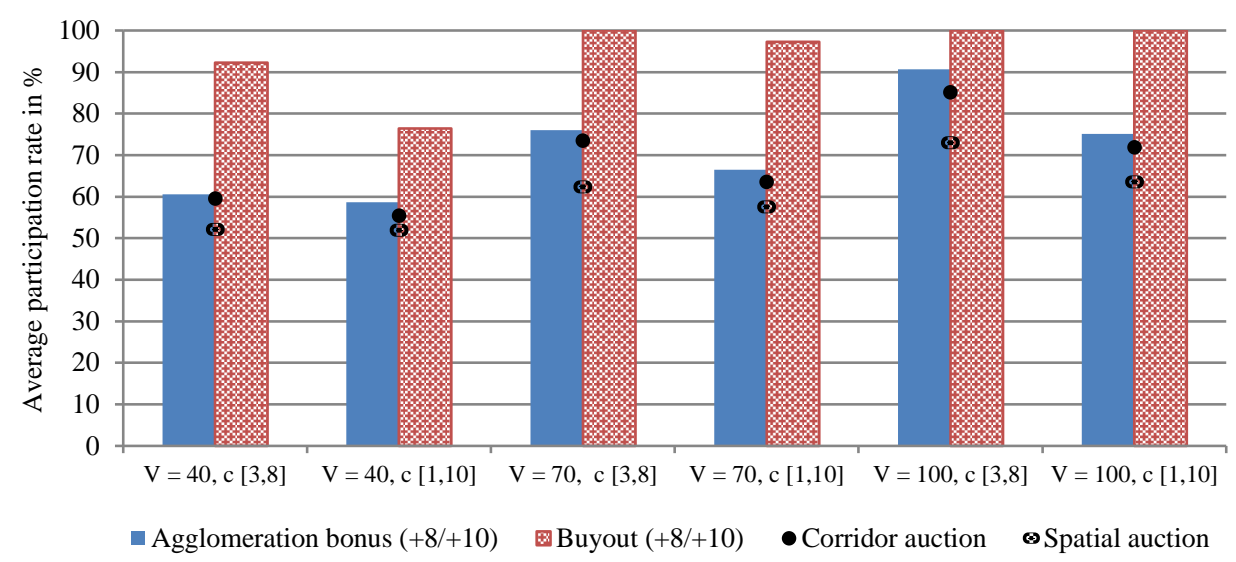

Note that the participation rate is based on $x$ out of 9 landowners in the $\mathrm{SA}, \mathrm{CA}$ and $\mathrm{AB}$ scenarios, while in the BO scenario it is based on $x$ out of 6 remaining landowners since landowner 5 has received a buyout compensation and landowners 2 and 8 do not participate by definition.

When comparing policy scenarios $\mathrm{AB}$ and $\mathrm{BO}$ to the benchmark $\mathrm{CA}$ in Figure 3, we find that $\mathrm{BO}$ outperforms $\mathrm{CA}$ in 5 out of 6 cases, while $\mathrm{AB}$ outperforms $\mathrm{CA}$ in only 2 out of 6 cases. ${ }^{25}$ Furthermore, $\mathrm{BO}$ is significantly more efficient than $\mathrm{AB}$ in 5 out of 6 cases (one-tailed t-tests, $p=0.0000$ ). The exception is the case with high corridor value $(V=100)$ and a narrow range of opportunity costs $c_{i} \in[3,8]$. When we consider this case in Figure 4, we see that the average participation rate of individual landowners is already very high in CA. Therefore, buying out the pivotal landowner is not efficient as he is already in the market most of the time (about $85 \%$ of the time in the $\mathrm{CA}$ benchmark for $V=100, c_{i} \in[3,8]$ ). AB has a larger effect on competition in this case as it increases participation rates for landowners 2 and 8, while in BO landowners 2 and 8 cannot participate in the auction. Hence, if participation rates are already very high in the CA benchmark, it is not efficient to buyout a pivotal player prior to holding the auction. However, in this case, offering an agglomeration bonus to the winning coalition is efficient and increases market performance of the corridor auction.

\footnotetext{
${ }^{24}$ One-tailed t-tests, $p=0.0000$ for all average bids and participation rates in all six cases. Note that in all six cases, participation rates are also significantly higher in the policy instrument scenarios (AB and BO) than in the CA benchmark (one-tailed t-tests, $p=0.0000$ ).

${ }^{25}$ For the BO scenario, one-tailed t-tests against the CA benchmark result in $p=0.0000$ in 4 out of 6 cases and $p=0.0001$ in the " $V=40$, $c_{i} \in[1,10]$ " case. For the AB scenario, one-tailed t-tests against the CA benchmark result in $p=0.0000$ in both the " $V=100$ " cases. In the " $V=70, c_{i} \in[3,8]$ " and the " $V=70, c_{i} \in[1,10]$ " cases, bids are in fact significantly smaller in the CA benchmark as compared to the AB scenario (one-tailed t-tests, $p=0.0173$ and $p=0.0002$, respectively).
} 
Figure 5. Average winning coalition bids ( $\mathrm{AB} 2$ and $\mathrm{BO} 2)$.

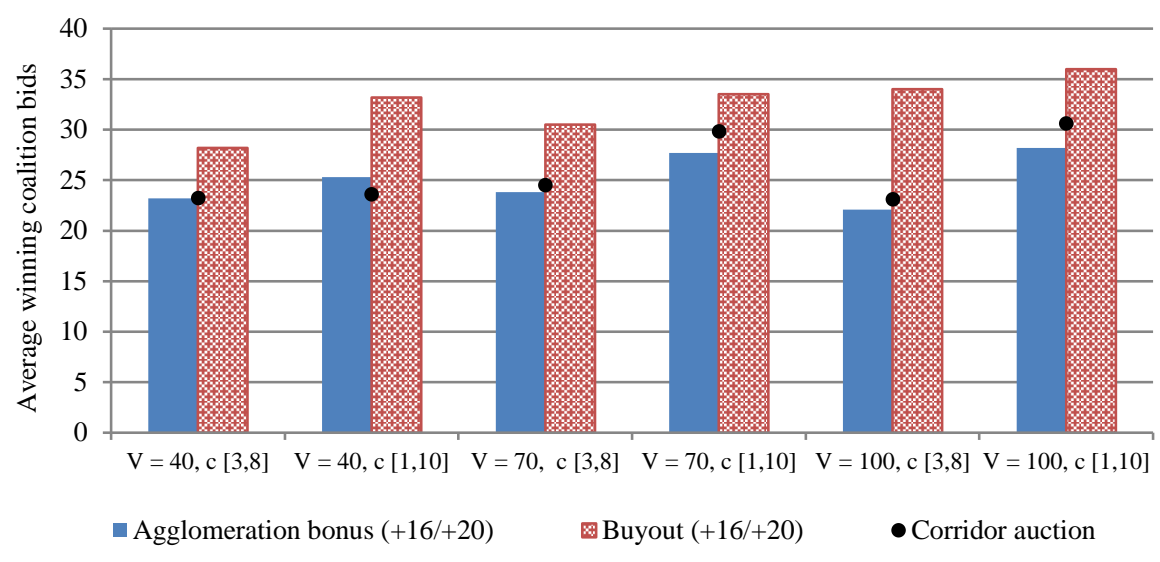

Note that the agglomeration bonus/buyout compensation is added to the winning coalition bid to ease comparison. The size of the bonus or the compensation is either equal to 8 or 10 depending on the opportunity cost range that applies.

Next, consider how the size of the bonus affects participation rates and bidding behavior. In Figure 5, we show the average winning coalition bids of $\mathrm{AB} 2$ and $\mathrm{BO} 2$ in which the agglomeration bonus and the buyout compensation are doubled - the bonus/compensation is equal to 16 for the narrow opportunity cost range cases $\left(c_{i} \in[3,8]\right)$ and 20 for the wide range cases $\left(c_{i} \in[1,10]\right)$. For these double bonus/compensation values, $\mathrm{AB} 2$ outperforms the benchmark CA in 4 out of 6 cases. When comparing Figures 3 and 5, doubling the bonus also made the agglomeration bonus efficient for " $V=70, c_{i} \in[3,8]$ " and " $V=70, c_{i} \in[1,10]$ " - cases in which participation is already relatively high. As is apparent in Figure 5, a buyout compensation that is double the size of the highest opportunity cost a single player can have in this landscape is less efficient than an agglomeration bonus - it is less efficient than the CA benchmark in all six cases. ${ }^{26}$

It can be shown that, with respect to windfall profits, there are no reasons for concern when doubling the agglomeration bonus (see Figures 9 and 10 in the online Appendix). It turns out that $\mathrm{AB}$ always has lower windfall profits for winning coalitions than the CA benchmark, and in 5 out of 6 cases, increased competition due to a higher agglomeration bonus in fact causes windfall profits to decrease in $\mathrm{AB} 2$ compared to $\mathrm{AB}$. The BO scenario also always features lower windfall profits for the winning coalitions than the CA benchmark they are in fact lower than in the $\mathrm{AB}$ scenario in 5 out of 6 of the cases. $\mathrm{In} \mathrm{BO} 2$, however, the double buyout compensation causes windfall profits to be higher than the CA benchmark in one of the cases. Surprisingly, a conservation agency that is concerned with windfall profits should thus opt for a high agglomeration bonus if sufficient funds allow him/her to do so. The main driver of these results is the increase in participation rates under $\mathrm{AB} 2$.

\footnotetext{
${ }^{26}$ Note however that in some cases in Figure 3 there is some room to increase the buyout compensation above $\bar{c}$ and still have the buyout be more efficient than the CA benchmark.
} 
Figure 6. $\mathrm{AB} / \mathrm{AB} 2$ and $\mathrm{BO} / \mathrm{BO} 2$ winning bid distributions for $V=70$ and $c_{i} \in[1,10]$.

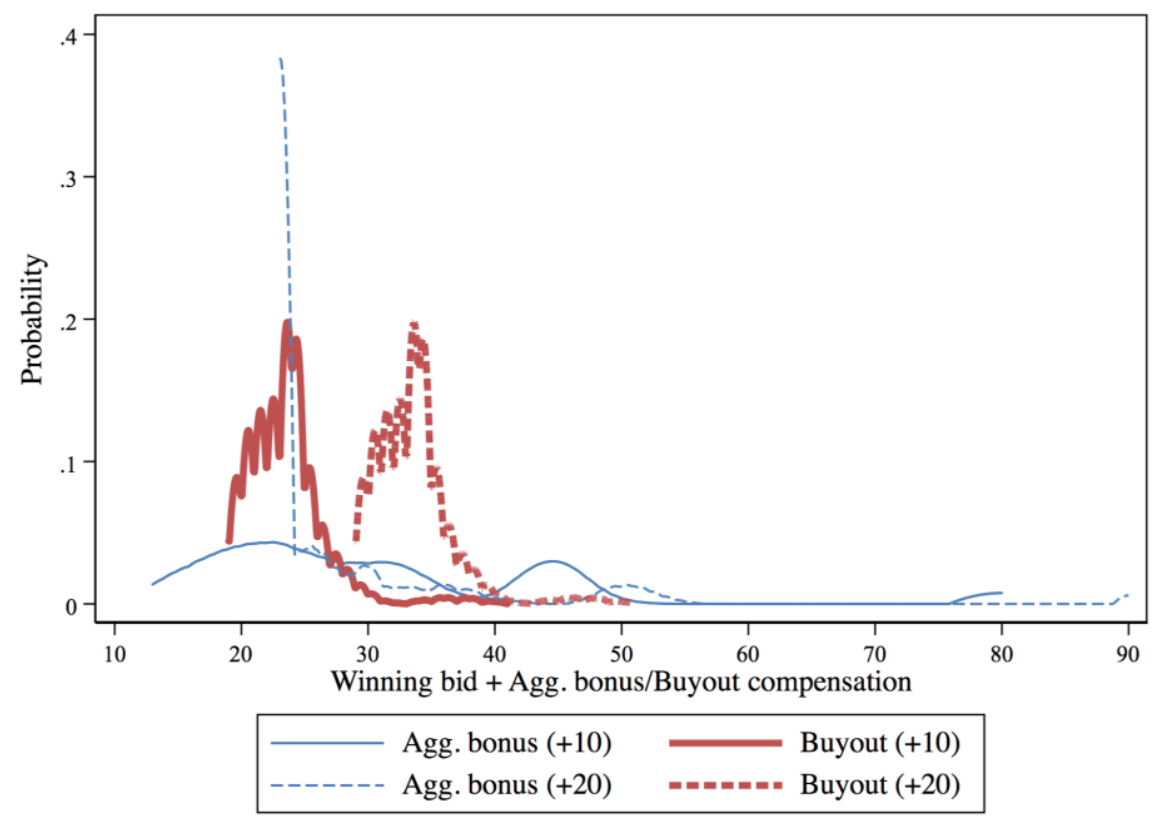

Note that the agglomeration bonus/buyout compensation is added to the winning coalition bid to ease comparison. The size of the bonus or the compensation is either equal to 10 or 20 depending on the policy scenario that applies. The $\mathrm{BO}$ and $\mathrm{BO} 2$ scenarios are depicted excluding simulations in which the corridor is not realized (see Table 4).

So far we have found that if participation rates are low, the increased competition (and the resulting decrease in bids) induced by strategic buyouts can reduce the overall costs incurred by the conservation agency. However, if participation rates are already high in the CA benchmark, the conservation agency is better off without a strategic buyout. Furthermore, for sufficiently generous agglomeration bonuses (AB2), we found that the bonus is more efficient than a strategic buyout (featuring a buyout compensation with the same size as the bonus; BO2). These results are all based on differences in average winning (coalition) bids, but what if a conservation agency is mostly concerned with avoiding high windfall profits and the possibility that he ends up procuring a corridor at a cost almost equal to the value of the corridor connecting the two existing conservation areas?

In Figure 6, we present the distributions of the winning coalition bids for $\mathrm{AB} / \mathrm{AB} 2$ and $\mathrm{BO} / \mathrm{BO} 2$ with parameter values $V=70$ and $c_{i} \in[1,10] .{ }^{27}$ We added the agglomeration bonus/buyout compensation to the coalition bid, so the horizontal axis has a maximum of 90 to account for the maximum coalition bid of 70 plus the (double) agglomeration bonus/buyout compensation of 20 . The average winning coalition bids (+ buyout compensations) in $\mathrm{BO}$ and $\mathrm{BO} 2$ are 23.5 and 33.5, respectively. Since in $\mathrm{BO} 2$ only the windfall profits change due to the higher buyout compensation, the standard deviation for both scenarios is similar and equals 3.11. In $\mathrm{AB}$ and $\mathrm{AB} 2$ the average winning coalition bids (+ agglomeration bonuses) are equal to 30.6 and 27.7 , and the standard deviations are much higher, 14.4 for $\mathrm{AB}$ and 9.75 for $\mathrm{AB} 2$. Clearly, the range of winning coalition bids is narrower for the buyout scenarios, and the reason for this is twofold. First, due to the relatively high participation rate for these parameter values (see Figure 4), winning coalition bids are never higher than 41 (51) in $\mathrm{BO}$ (BO2). Second, since the buyout decreases the potential number of initial corridors from 17 to 9 , winning

27 The distributions in the other cases are very similar. Table 3 in the online Appendix shows that the standard deviations of the winning coalition bids in the $\mathrm{AB} / \mathrm{AB} 2$ scenarios are always higher than those in the $\mathrm{BO} / \mathrm{BO} 2$ scenarios. 
coalitions bids are also never lower than 19 (29) in BO (BO2). In AB and AB2, however, the lowest observed bid, excluding the bonus, is 3 while it can also happen that a coalition obtains the entire value of the corridor as their profit in the auction. ${ }^{28}$ When comparing AB with AB2, we see that the higher agglomeration bonus causes a large increase of low winning bids and a decrease in winning bids between 30 and 50. However, even with the higher bonus in $\mathrm{AB} 2$, the conservation agency is still at risk of procuring the corridor at a price equal to the value of connecting the two existing conservation areas (or even higher when taking into account the bonus payment).

The previous results come with two important disclaimers. First, note that the conservation agency only uses funds for the agglomeration bonus if the corridor is realized. In $\mathrm{BO}$ and $\mathrm{BO} 2$, the buyout takes place prior to the auction and thus the conservation agency has to invest funds regardless of the corridor being realized in the auction that follows. For $V=40$ and both ranges of opportunity costs and also for $V=70$ and $c_{i} \in[1,10]$, the corridor is not always realized (see Table 4 in the online Appendix and also Figure 4). ${ }^{29}$ These instances, however, are few: 68,516 , and 19 out of 10,000 simulations for the three cases respectively. Since these are very small percentages, adding these 'wasted funds' to the windfall profits of Figures 9 and 10 does not change our results. If added to the distributions in Figure 6, however, the few simulations in which the corridor has not been realized could be depicted as a probability of $.0019(=19 / 10,000)$ that a buyout compensation of 10 (or 20 for the $\mathrm{BO} 2$ scenario) is allocated to landowner 5. The conservation agency thus runs the risk of leaving large windfall profits with winning coalitions under the agglomeration bonus scenarios, but under the buyout scenarios there is a small possibility of the conservation agency leaving large windfall profits with the pivotal player and ending up without a viable corridor. ${ }^{30}$

The second disclaimer also concerns windfall profits, but now for the pivotal player that receives the buyout compensation. We assumed that the buyout was mandatory and that since the buyout compensation is equal to $\bar{c}$ or $2 \bar{c}$, landowner 5 would make a profit or at least break even in the BO scenario and always make a profit in the BO2 scenario. Alternatively, consider a voluntary buyout. Would a risk neutral landowner 5 agree with the buyout or prefer to join the auction? In Table 4 in the online Appendix, windfall profits of landowner 5 are given for the two buyout scenarios and the CA benchmark in all six cases. Here, we describe the " $V=40$, $c_{i} \in[3,8]$ " case. Expected windfall profits for landowner 5 are constant in the mandatory buyout scenarios. The expected opportunity costs are 5.5 for $c_{i} \in[3,8]$ and the compensation is either equal to 8 or 16 . Hence, expected windfall profits are equal to $8-5.5=2.5$ and $16-5.5=10.5$ for $\mathrm{BO}$ and $\mathrm{BO} 2$ respectively. ${ }^{31}$ Now, for a voluntary buyout we have to check whether these expected windfall profits are larger than in the CA scenario. In 3,211 out of 10,000 simulations, landowner 5 was part of the winning coalition, and his average windfall profits are equal to 2.9 in this specific CA scenario. The expected windfall profits of refusing the buyout and joining the auction are thus equal to $2.9 \times(3211 / 10000)=0.9$. Clearly, expected profits are higher in the $\mathrm{BO}$ and $\mathrm{BO} 2$ scenarios. Still, a risk loving landowner could prefer not to opt for the buyout compensation as he could obtain windfall profits up to 10 in $\mathrm{CA}$, while in $\mathrm{BO}$ the windfall profits reach a maximum of 5 (for the

\footnotetext{
${ }^{28}$ Recall that a bid equal to zero is not allowed, so the minimum coalition bid is equal to 3 .

${ }^{29}$ In the other three cases the corridor is realized in all 10,000 simulations; landowner participations rates are $100 \%$ in every simulation.

${ }^{30}$ Fooks et al. (2016) also find that selection mechanisms that target parcels with "high quality contiguous attributes" might lead to pivotal landowners extracting surplus rents from conservation programs.

31 These values are rounded. Average opportunity costs are in the $[5.45,5.52]$ range for our simulations (see Table 4 in the online Appendix).
} 
lowest opportunity cost draw). In the BO2 scenario however, windfall profits go up to 13 making it the preferred choice even for risk loving landowners.

To summarize, our simulation results have shown that small agglomeration bonuses have limited effect as they increase participation rates only by a little, thus making the resulting reduction in the winning coalition bids too small to account for the added costs of offering the bonus. Using the funds required for such a bonus to buyout just one pivotal player could drastically improve results. The buyout has a larger effect on participation rates and thus reduces winning coalition bids by such an amount that the funds required for the compensation are more than accounted for - the conservation agency ends up with higher net benefits in most cases. When we double the agglomeration bonus however, the bonus is more efficient than the buyout in all cases. Nevertheless, a conservation agency that wishes to avoid the risk of very costly procurement (possibly making a net loss when taking into account the bonus payment) is better off using the buyout policy. The reason is that the buyout simulations feature a narrower range of procurement costs. Hence, although the average winning coalition bids are lower in the corridor auction with the agglomeration bonus, opting for the buyout policy before the auction takes place reduces the risk that the corridor has to be procured at a very high cost.

\section{Conclusion}

The current literature on agglomeration bonuses for spatial auctions offers a limited perspective on the effect of the bonus on bidding behavior. Experimental studies on the agglomeration bonus typically use arbitrarily (fixed) corridor values and opportunity costs and assume that participation is mandatory in studying the effectiveness of the bonus (Parkhurst and Shogren 2008). We push the literature forward by introducing a model that can predict the bids of heterogeneous landowners, the participation rates and the net benefit of procuring a wildlife corridor through a wildlife corridor auction. The model can be fitted to hold for any spatial configuration and any border rule that determines what constitutes a viable corridor between two existing nature conservation areas. Our simulation results show that a small agglomeration bonus does not work and using these funds instead to buyout just one pivotal player can drastically improve results. Larger agglomeration bonuses are however more efficient than a buyout. Nevertheless, a conservation agency that wishes to avoid the risk of procuring a corridor at very high costs (possibly making a net loss when taking into account the bonus payment) is better off using the buyout policy. A legal provision called eminent domain empowers many governments around the world to acquire a private property for public purposes with due compensation. And although such laws can be criticized on political and social grounds ( $c f$. Miceli 2011, Sarkan 2016), our results show that an economic conflict might not necessarily arise for those that are offered a buyout compensation.

Our model can be extended by adding risk preferences to the participation decisions. This paper shows that participation decisions are a crucial factor in the efficiency of spatial procurement auctions, and with risk averse landowners, the effect of these decisions on auction outcomes is expected to intensify. Combining this with the fact that participation rates in procurement auctions are very low in practice (cf. Brown et al. 2011, Bartolini et al. 2013, DePiper et al. 2013), it is important to establish the potential success of agglomeration bonuses or strategic buyouts in realizing higher participation rates. The next step in this research would be to apply our model to real-world wildlife corridor auction design. The hypothetical landscape used in our simulations is conducive for good performance of the buyout scenario. In other landscapes, say larger ones ( $c f$. Conrad et al. 
2012) or landscapes without clear strategic positions, the buyout of just one landowner may result in lower market efficiency of the buyout policy.

\section{References}

Ando, A., J. Camm, S. Polasky, and A. Solow (1998). Species distributions, land values, and efficient conservation, Science 279(5359): 2126-2128.

Bamière, L., M. David, and B. Vermont (2013). Agri-environmental policies for biodiversity when the spatial pattern of the reserve matters, Ecological Economics 85: 97-104.

Bartolini, F., G. Brunori, L. Fastelli, and M. Rovai (2013). Understanding the participation in agrienvironmental schemes: Evidence from Tuscany region, ERSA conference papers, ersa13p1084.

Brown, L.K., E. Troutt, C. Edwards, B. Gray, and W. Hu (2011). A uniform price auction for conservation easements in the Canadian Prairies, Environmental and Resource Economics 50(1): 49-60.

Camerer, C.F., and E.J. Johnson (2004). Thinking about attention in games: Backward and forward induction. In: I. Brocas, and J.D. Carrillo (Eds.), The Psychology of Economic Decisions 2: 111-130.

Cason, T.N. (1993). Seller Incentive Properties of EPA's emission trading auction, Journal of Environmental Economics and Management 25(2): 177-195.

Conrad, J. M., C.P. Gomes, W.J. van Hoeve, A. Sabharwal, and J.F. Suter (2012). Wildlife corridors as a connected subgraph problem, Journal of Environmental Economics and Management 63(1): 1-18.

Cramton, P., and J.A. Schwartz (2000). Collusive bidding: Lessons from the FCC spectrum auctions, Journal of Regulatory Economics 17(3): 229-252.

DePiper, G.S., N. Higgins, D.W. Lipton, and A. Stocking (2013). Auction design, incentives, and buying back Maryland and Virginia crab licenses, Canadian Journal of Agricultural Economics 61(2): 353-370.

Drechsler, M., F. Wätzold, K. Johst, and J.F. Shogren (2010). An agglomeration payment for cost-effective biodiversity conservation in spatially structured landscapes, Resource and Energy Economics 32(2): 261-275.

Fooks, J.R., N. Higgins, K.D. Messer, J.M. Duke, D. Hellerstein, and L. Lynch (2016). Conserving spatially explicit benefits in ecosystem service markets: Experimental tests of network bonuses and spatial targeting, American Journal of Agricultural Economics 98(2): 468-488.

Haddad, N.M., L.A. Brudvig, J. Clobert, K.F. Davies, A. Gonzalez, R.D. Holt, ..., and J.R. Townshend (2015). Habitat fragmentation and its lasting impact on Earth's ecosystems, Science Advances 1(2): 1-9.

Iftekhar, M.S., and J.G. Tisdell (2014). Wildlife corridor market design: An experimental analysis of the impact of project selection criteria and bidding flexibility, Ecological Economics 104: 50-60.

Iftekhar, M.S., and J.G. Tisdell (2016). An agent based analysis of combinatorial bidding for spatially targeted multi-objective environmental programs, Environmental and Resource Economics 64(4): 537-558.

Jackson, M.O. (2005). Allocation rules for network games, Games and Economic Behavior 51(1): 128-154.

Johnson, E.J., C. Camerer, S. Sen, and T. Rymon (2002). Detecting failures of backward induction: Monitoring information search in sequential bargaining, Journal of Economic Theory 104(1): 16-47. 
Krawczyk, M., A. Bartczak, N. Hanley, and A. Stenger (2016). Buying spatially-coordinated ecosystem services: An experiment on the role of auction format and communication, Ecological Economics 124: $36-48$.

Latacz-Lohmann, U., and C. van der Hamsvoort (1998). Auctions as a means of creating a market for public goods from agriculture, Journal of Agricultural Economics 49(3): 334-345.

Latacz-Lohmann, U., and S. Schilizzi (2005). Auctions for conservation contracts: A review of the theoretical and empirical literature, Report to the Scottish executive environment and rural affairs department.

Macho-Stadler, I., D. Pérez-Castrillo, and D. Wettstein (2007). Sharing the surplus: An extension of the Shapley value for environments with externalities, Journal of Economic Theory 135(1): 339-356.

Margules, C.R., and R.L. Pressey (2000). Systematic conservation planning, Nature 405(6783): 243-253.

Miceli, T.J. (2011). The economic theory of eminent domain: private property, public use, Cambridge University Press, New York, USA.

Parkhurst, G.M., J.F. Shogren, C. Bastian, P. Kivi, J. Donner, and R.B.W. Smith (2002). Agglomeration bonus: An incentive mechanism to reunite fragmented habitat for biodiversity conservation, Ecological Economics 41: 305-328.

Parkhurst, G.M., and J.F. Shogren (2007). Spatial incentives to coordinate contiguous habitat, Ecological Economics 64(2): 344-355.

Parkhurst, G.M., and J.F. Shogren (2008). Smart subsidies for conservation, American Journal of Agricultural Economics 90(5): 1192-1200.

Parkhurst, G.M., J.F. Shogren, and T. Crocker (2016). Tradable set-aside requirements (TSARs): conserving spatially dependent environmental amenities, Environmental and Resource Economics 63(4): 719-744.

Roth, A.E. (1988). The Shapley value: Essays in honor of Lloyd S. Shapley, Cambridge University Press, Cambridge, UK.

Sarkar, S. (2016). Mechanism design for land acquisition, International Journal of Game Theory: 1-30.

Stoneham, G., V. Chaudhri, A. Ha, and L. Strappazzon (2003). Auctions for conservation contracts: An empirical examination of Victoria's BushTender trial, Australian Journal of Agricultural and Resource Economics 47(4): 477-500.

Wätzold, F., and M. Drechsler (2005). Spatially uniform versus spatially heterogeneous compensation payments for biodiversity-enhancing land-use measures, Environmental and Resource Economics 31(1): 73-93.

Williams, J.C. (1998). Delineating protected wildlife corridors with multi objective programming, Environmental Modeling and Assessment 3(1-2): 77-86.

Williams, K.J., A.F. Reeson, M.J. Drielsma, and J. Love (2012). Optimised whole-landscape ecological metrics for effective delivery of connectivity-focused conservation incentive payments, Ecological Economics 81: 48-59.

Williams, J.C., and S.A. Snyder (2005). Restoring habitat corridors in fragmented landscapes using optimization and percolation models, Environmental Modeling and Assessment 10(3): 239-250.

Windle, J., J. Rolfe, S. Whitten, and J. McCosker (2005). A competitive bidding process with landholder cooperation for landscape linkage, Paper presented at the 49th annual conference of the Australian Agricultural and Resource Economics Society, Coffs Harbour, Australia. 


\section{Appendix}

\section{A. Proof Proposition 1}

Proposition 1: For any $V-B_{S}^{*}>0$ and $n \geq 2$, we have that $B_{S}^{*}$ is decreasing in $n$, i.e. $\frac{d B_{S}^{*}}{d n}<0$.

Proof. Any viable coalition $S$ chooses $B_{S}^{*}$ in order to maximize its expected profits. We derive the FOC of this maximization problem in (4), and we substitute $\alpha=V-B_{S}^{*}$ :

$$
\alpha=\left(\frac{-1}{n}\right) \frac{(\alpha+1)^{n}-\alpha^{n}}{(\alpha+1)^{n-1}-\alpha^{n-1}}+\left(V-C_{S}\right)
$$

This is an implicit function of the form $\alpha=f(\alpha, n)$. Using implicit differentiation, we obtain

$$
d \alpha=f_{\alpha} d \alpha+f_{n} d n, \text { or } \frac{d \alpha}{d n}=\frac{f_{n}}{1-f_{\alpha}}
$$

and we find:

$$
\frac{d \alpha}{d n}=\frac{\alpha(\alpha+1)\left[(\alpha+1) \alpha^{2 n}+\alpha(\alpha+1)^{2 n}-2 \alpha^{n+1}(\alpha+1)^{n}+[\ln (\alpha+1)-\ln (\alpha)] \alpha^{n}(\alpha+1)^{n} n-\alpha^{n}(\alpha+1)^{n}\right]}{n\left[(n+1) \alpha^{2 n}(\alpha+1)^{2}+(n+1) \alpha^{2}(\alpha+1)^{2 n}-(n+1) 2 \alpha^{n+1}(\alpha+1)^{n+1}+(n-1) \alpha^{n}(\alpha+1)^{n}\right]} .
$$

We proceed to check its sign. The numerator is strictly positive if:

$$
2+\frac{1}{\alpha}<\left(\frac{\alpha}{\alpha+1}\right)^{n-1}+\left(\frac{\alpha+1}{\alpha}\right)^{n}+\frac{n}{\alpha}[\ln (\alpha+1)-\ln (\alpha)] .
$$

The last RHS term is strictly positive for any $\alpha>0, n \geq 1$. The combination of the first two RHS terms is always larger than $2+\frac{1}{\alpha}$ for any $\alpha>0, n \geq 2$ and equal to $2+\frac{1}{\alpha}$ for any $\alpha>0, n=1$. Therefore, this inequality holds for any $\alpha>0, n \geq 2$.

The denominator is strictly positive if:

$$
2<\left(\frac{\alpha}{\alpha+1}\right)^{n-1}+\left(\frac{\alpha+1}{\alpha}\right)^{n-1}+\frac{n-1}{(n+1) \alpha(\alpha+1)}
$$

The last RHS term is strictly positive for any $\alpha \geq 0, n \geq 2$. The combination of the first two RHS terms is always larger than 2 for any $\alpha \geq 0, n \geq 3$ and equal to 2 for any $\alpha \geq 0, n \in\{1,2\}$. Therefore, this inequality holds for any $\alpha \geq 0, n \geq 2$. Combining the strictly positive signs of the numerator and denominator on the indicated domains, we find that $\frac{d \alpha}{d n}>0$ for any $\alpha>0, n \geq 2$. Substituting back $\alpha=V-B_{S}^{*}$ and because $V$ is fixed, this implies that $\frac{d B_{S}^{*}}{d n}<0$ for any $\alpha>0, n \geq 2$. 


\section{B. Additional figures}

Figure 7. Viable corridors and unconnected coalitions.

Set of 17 viable corridors:
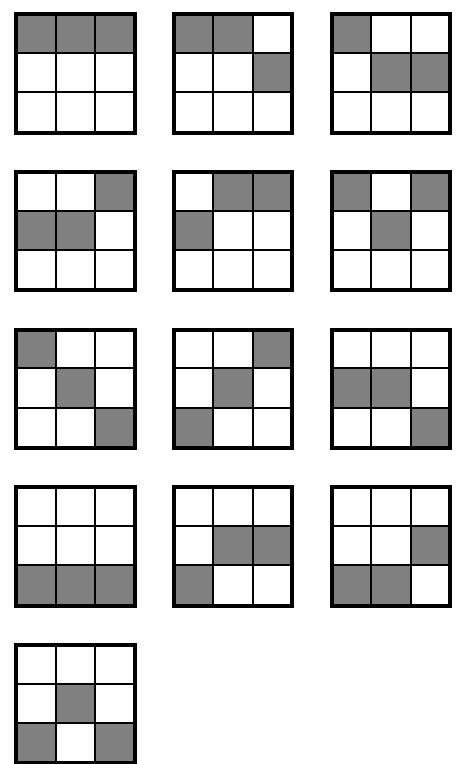

Set of 10 unconnected coalitions:
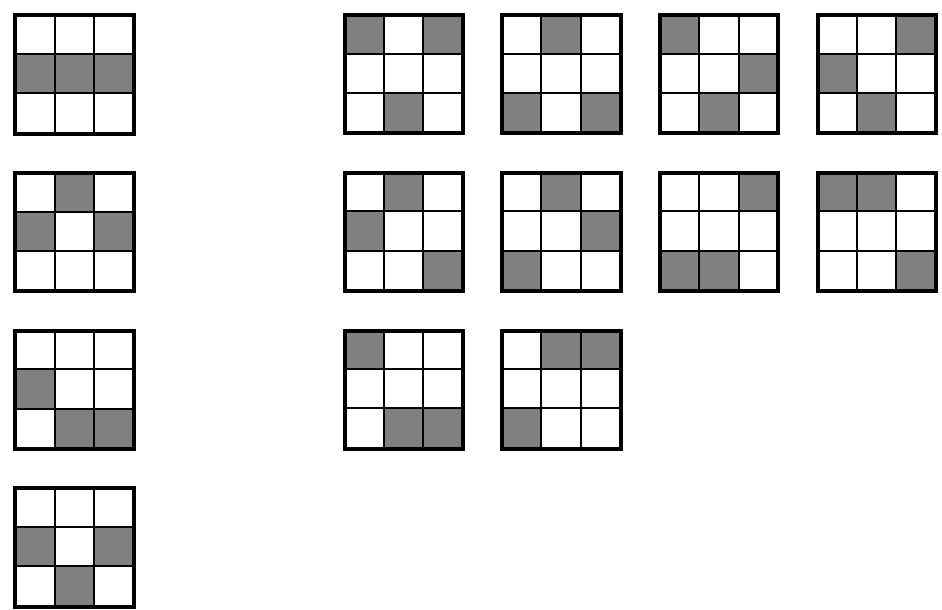

Figure 8. Number of coalitions an individual landowner is able to join.

Spatial auction scenario:

\begin{tabular}{|l|l|l|}
\hline 9 & 9 & 9 \\
\hline 9 & 9 & 9 \\
\hline 9 & 9 & 9 \\
\hline & & \\
\hline
\end{tabular}

(out of 27)
Corridor auction scenario:

\begin{tabular}{|l|l|l|}
\hline 5 & 4 & 5 \\
\hline 7 & 9 & 7 \\
\hline 5 & & \\
\hline & 4 & 5 \\
\hline
\end{tabular}

(out of 17) 
Table 2. Detailed simulation results for the different policy scenarios.

\begin{tabular}{|c|c|c|c|}
\hline$V=40, c \in[3,8]$ & Average bid & Average winning bid & $\begin{array}{c}\text { Average participation } \\
\text { rate }(\%)\end{array}$ \\
\hline Spatial auction (SA) & $\begin{array}{c}18.7 \\
(4.20)\end{array}$ & $\begin{array}{c}20.2 \\
(5.49)\end{array}$ & $\begin{array}{c}52.0 \\
(10.3)\end{array}$ \\
\hline Corridor auction (CA) & $\begin{array}{c}20.9 \\
(5.22) \\
\end{array}$ & $\begin{array}{c}23.2 \\
(7.20)\end{array}$ & $\begin{array}{l}59.5 \\
(10.0)\end{array}$ \\
\hline Agglomeration bonus $(A B)$ & $\begin{array}{c}22.4 \\
(6.56)\end{array}$ & $\begin{array}{c}25.8 \\
(9.24)\end{array}$ & $\begin{array}{c}60.6 \\
(10.6)\end{array}$ \\
\hline Buyout (BO) & $\begin{array}{c}22.2 \\
(2.23) \\
\end{array}$ & $\begin{array}{c}20.2 \\
(2.38) \\
\end{array}$ & $\begin{array}{c}92.3 \\
(11.1) \\
\end{array}$ \\
\hline$V=40, c \in[1,10]$ & Average bid & Average winning bid & $\begin{array}{c}\text { Average participation } \\
\text { rate }(\%)\end{array}$ \\
\hline Spatial auction (SA) & $\begin{array}{c}16.6 \\
(4.97) \\
\end{array}$ & $\begin{array}{c}17.8 \\
(6.28) \\
\end{array}$ & $\begin{array}{c}51.8 \\
(10.2) \\
\end{array}$ \\
\hline Corridor auction (CA) & $\begin{array}{c}20.6 \\
(6.90) \\
\end{array}$ & $\begin{array}{c}23.6 \\
(8.95) \\
\end{array}$ & $\begin{array}{c}55.4 \\
(10.1)\end{array}$ \\
\hline Agglomeration bonus (AB) & $\begin{array}{c}21.7 \\
(8.10)\end{array}$ & $\begin{array}{c}25.8 \\
(11.1)\end{array}$ & $\begin{array}{c}58.7 \\
(10.8)\end{array}$ \\
\hline Buyout (BO) & $\begin{array}{c}24.7 \\
(3.51) \\
\end{array}$ & $\begin{array}{c}23.2 \\
(3.58) \\
\end{array}$ & $\begin{array}{c}76.4 \\
(13.2) \\
\end{array}$ \\
\hline$V=70, c \in[3,8]$ & Average bid & Average winning bid & $\begin{array}{c}\text { Average participation } \\
\text { rate }(\%)\end{array}$ \\
\hline Spatial auction (SA) & $\begin{array}{c}21.7 \\
(5.18) \\
\end{array}$ & $\begin{array}{c}23.2 \\
(6.80) \\
\end{array}$ & $\begin{array}{c}62.2 \\
(10.5) \\
\end{array}$ \\
\hline Corridor auction (CA) & $\begin{array}{c}22.9 \\
(5.61) \\
\end{array}$ & $\begin{array}{c}24.5 \\
(8.77) \\
\end{array}$ & $\begin{array}{c}73.5 \\
(10.7) \\
\end{array}$ \\
\hline Agglomeration bonus $(A B)$ & $\begin{array}{c}23.6 \\
(5.47) \\
\end{array}$ & $\begin{array}{c}24.8 \\
(8.51) \\
\end{array}$ & $\begin{array}{c}76.0 \\
(10.8) \\
\end{array}$ \\
\hline Buyout $(B O)$ & $\begin{array}{c}25.1 \\
(2.28) \\
\end{array}$ & $\begin{array}{c}22.5 \\
(1.27) \\
\end{array}$ & $\begin{array}{c}100 \\
(0.00) \\
\end{array}$ \\
\hline$V=70, c \in[1,10]$ & Average bid & Average winning bid & $\begin{array}{c}\text { Average participation } \\
\text { rate }(\%)\end{array}$ \\
\hline Spatial auction (SA) & $\begin{array}{c}21.6 \\
(6.84) \\
\end{array}$ & $\begin{array}{c}23.3 \\
(8.76) \\
\end{array}$ & $\begin{array}{c}57.4 \\
(10.0) \\
\end{array}$ \\
\hline Corridor auction (CA) & $\begin{array}{c}25.6 \\
(9.55) \\
\end{array}$ & $\begin{array}{c}29.8 \\
(13.9) \\
\end{array}$ & $\begin{array}{c}63.5 \\
(10.4) \\
\end{array}$ \\
\hline Agglomeration bonus $(A B)$ & $\begin{array}{c}26.6 \\
(9.77) \\
\end{array}$ & $\begin{array}{c}30.6 \\
(14.4) \\
\end{array}$ & $\begin{array}{c}66.5 \\
(10.4) \\
\end{array}$ \\
\hline Buyout $(B O)$ & $\begin{array}{c}27.4 \\
(3.65) \\
\end{array}$ & $\begin{array}{c}23.5 \\
(3.11) \\
\end{array}$ & $\begin{array}{c}97.3 \\
(7.20) \\
\end{array}$ \\
\hline$V=100, c \in[3,8]$ & Average bid & Average winning bid & $\begin{array}{l}\text { Average participation } \\
\text { rate }(\%)\end{array}$ \\
\hline Spatial auction $(S A)$ & $\begin{array}{c}22.4 \\
(4.70) \\
\end{array}$ & $\begin{array}{c}22.6 \\
(6.17) \\
\end{array}$ & $\begin{array}{c}72.9 \\
(10.6) \\
\end{array}$ \\
\hline Corridor auction (CA) & $\begin{array}{c}23.6 \\
(4.58)\end{array}$ & $\begin{array}{c}23.1 \\
(7.06)\end{array}$ & $\begin{array}{c}85.1 \\
(10.2)\end{array}$ \\
\hline Agglomeration bonus $(A B)$ & $\begin{array}{c}23.2 \\
(3.76)\end{array}$ & $\begin{array}{c}21.2 \\
(5.29)\end{array}$ & $\begin{array}{c}90.7 \\
(9.33)\end{array}$ \\
\hline
\end{tabular}


Table 2. Continued.

\begin{tabular}{|c|c|c|c|}
\hline Buyout $(B O)$ & $\begin{array}{c}28.4 \\
(2.03) \\
\end{array}$ & $\begin{array}{c}26.0 \\
(1.46) \\
\end{array}$ & $\begin{array}{c}100 \\
(0.00) \\
\end{array}$ \\
\hline$V=100, c \in[1,10]$ & Average bid & Average winning bid & $\begin{array}{c}\text { Average participation } \\
\text { rate }(\%)\end{array}$ \\
\hline Spatial auction (SA) & $\begin{array}{c}24.3 \\
(7.55)\end{array}$ & $\begin{array}{c}25.6 \\
(9.61)\end{array}$ & $\begin{array}{c}63.4 \\
(10.1)\end{array}$ \\
\hline Corridor auction (CA) & $\begin{array}{c}27.7 \\
(9.53)\end{array}$ & $\begin{array}{c}30.6 \\
(14.2)\end{array}$ & $\begin{array}{c}71.8 \\
(10.6)\end{array}$ \\
\hline Agglomeration bonus (AB) & $\begin{array}{c}27.7 \\
(8.89) \\
\end{array}$ & $\begin{array}{c}29.5 \\
(13.8) \\
\end{array}$ & $\begin{array}{c}75.1 \\
(10.5)\end{array}$ \\
\hline Buyout (BO) & $\begin{array}{c}30.4 \\
(3.66)\end{array}$ & $\begin{array}{c}26.0 \\
(2.59)\end{array}$ & $\begin{array}{c}100 \\
(0.00)\end{array}$ \\
\hline
\end{tabular}

Average (winning) bids are displayed for the coalitions and participation rates are given in percentages for the individual landowners. The results of every treatment and parameter value combination is based on 10,000 auction simulations in which opportunity costs are randomly assigned to the individual landowners from the parameter range depicted in the table. Note that the agglomeration bonus and the buyout costs of 8 or 10 (depending on the max. opportunity costs) are added to the Agglomeration bonus (AB) and Buyout (BO) scenarios' (winning) bids for the ease of comparison. Standard deviations are in parentheses.

Table 3. Detailed simulation results for $\mathrm{AB} / \mathrm{AB} 2$ and $\mathrm{BO} / \mathrm{BO} 2$.

\begin{tabular}{|c|c|c|c|}
\hline$V=40, c \in[3,8]$ & Average winning bid & $\begin{array}{l}\text { Average windfall } \\
\text { profits }\end{array}$ & $\begin{array}{c}\text { Average participation } \\
\text { rate }(\%)\end{array}$ \\
\hline Agglomeration bonus (AB) & $\begin{array}{c}25.8 \\
(9.24)\end{array}$ & $\begin{array}{c}13.7 \\
(8.84)\end{array}$ & $\begin{array}{c}60.6 \\
(10.6)\end{array}$ \\
\hline Buyout (BO) & $\begin{array}{c}20.2 \\
(2.38)\end{array}$ & $\begin{array}{c}6.64 \\
(2.66)\end{array}$ & $\begin{array}{c}92.3 \\
(11.1)\end{array}$ \\
\hline Agglomeration bonus (AB2) & $\begin{array}{c}23.2 \\
(6.82) \\
\end{array}$ & $\begin{array}{c}10.9 \\
(6.52)\end{array}$ & $\begin{array}{c}72.5 \\
(11.6) \\
\end{array}$ \\
\hline Buyout (BO2) & $\begin{array}{c}28.2 \\
(2.38) \\
\end{array}$ & $\begin{array}{c}14.6 \\
(2.66) \\
\end{array}$ & $\begin{array}{c}92.3 \\
(11.1) \\
\end{array}$ \\
\hline$V=40, c \in[1,10]$ & Average winning bid & $\begin{array}{l}\text { Average windfall } \\
\text { profits }\end{array}$ & $\begin{array}{c}\text { Average participation } \\
\text { rate }(\%)\end{array}$ \\
\hline Agglomeration bonus $(A B)$ & $\begin{array}{c}25.8 \\
(11.1)\end{array}$ & $\begin{array}{c}17.0 \\
(10.2)\end{array}$ & $\begin{array}{c}58.7 \\
(10.8)\end{array}$ \\
\hline Buyout (BO) & $\begin{array}{c}23.2 \\
(3.58)\end{array}$ & $\begin{array}{c}11.8 \\
(4.34)\end{array}$ & $\begin{array}{c}76.4 \\
(13.2)\end{array}$ \\
\hline Agglomeration bonus (AB2) & $\begin{array}{c}25.3 \\
(6.20)\end{array}$ & $\begin{array}{c}15.9 \\
(5.98)\end{array}$ & $\begin{array}{c}74.0 \\
(12.2)\end{array}$ \\
\hline Buyout (BO2) & $\begin{array}{c}33.2 \\
(3.58) \\
\end{array}$ & $\begin{array}{c}21.8 \\
(4.34) \\
\end{array}$ & $\begin{array}{c}76.4 \\
(13.2) \\
\end{array}$ \\
\hline$V=70, c \in[3,8]$ & Average winning bid & $\begin{array}{l}\text { Average windfall } \\
\text { profits }\end{array}$ & $\begin{array}{c}\text { Average participation } \\
\text { rate }(\%)\end{array}$ \\
\hline Agglomeration bonus $(A B)$ & $\begin{array}{c}24.8 \\
(8.51)\end{array}$ & $\begin{array}{c}12.4 \\
(8.46)\end{array}$ & $\begin{array}{c}76.0 \\
(10.8)\end{array}$ \\
\hline Buyout (BO) & $\begin{array}{c}22.5 \\
(1.27)\end{array}$ & $\begin{array}{c}8.89 \\
(1.78)\end{array}$ & $\begin{array}{c}100 \\
(0.00)\end{array}$ \\
\hline Agglomeration bonus (AB2) & $\begin{array}{c}23.8 \\
(7.20)\end{array}$ & $\begin{array}{c}11.4 \\
(7.05)\end{array}$ & $\begin{array}{c}81.2 \\
(10.4)\end{array}$ \\
\hline Buyout (BO2) & $\begin{array}{c}30.5 \\
(1.27)\end{array}$ & $\begin{array}{c}16.9 \\
(1.78)\end{array}$ & $\begin{array}{c}100 \\
(0.00)\end{array}$ \\
\hline
\end{tabular}


Table 3. Continued.

\begin{tabular}{|c|c|c|c|}
\hline$V=70, c \in[1,10]$ & Average winning bid & $\begin{array}{l}\text { Average windfall } \\
\text { profits }\end{array}$ & $\begin{array}{c}\text { Average participation } \\
\text { rate }(\%)\end{array}$ \\
\hline Agglomeration bonus $(A B)$ & $\begin{array}{c}30.6 \\
(14.4)\end{array}$ & $\begin{array}{c}21.2 \\
(13.9)\end{array}$ & $\begin{array}{c}66.5 \\
(10.4)\end{array}$ \\
\hline Buyout (BO) & $\begin{array}{c}23.5 \\
(3.11)\end{array}$ & $\begin{array}{c}11.9 \\
(3.71)\end{array}$ & $\begin{array}{c}97.3 \\
(7.20)\end{array}$ \\
\hline Agglomeration bonus (AB2) & $\begin{array}{c}27.7 \\
(9.75)\end{array}$ & $\begin{array}{c}18.1 \\
(9.21)\end{array}$ & $\begin{array}{c}76.9 \\
(11.2)\end{array}$ \\
\hline Buyout (BO2) & $\begin{array}{c}33.5 \\
(3.11) \\
\end{array}$ & $\begin{array}{c}21.9 \\
(3.71) \\
\end{array}$ & $\begin{array}{c}97.3 \\
(7.20) \\
\end{array}$ \\
\hline$V=100, c \in[3,8]$ & Average winning bid & $\begin{array}{l}\text { Average windfall } \\
\text { profits }\end{array}$ & $\begin{array}{c}\text { Average participation } \\
\text { rate }(\%)\end{array}$ \\
\hline Agglomeration bonus (AB) & $\begin{array}{c}21.2 \\
(5.29)\end{array}$ & $\begin{array}{c}8.71 \\
(5.35)\end{array}$ & $\begin{array}{c}90.7 \\
(9.33)\end{array}$ \\
\hline Buyout (BO) & $\begin{array}{c}26.0 \\
(1.46)\end{array}$ & $\begin{array}{c}12.4 \\
(1.74)\end{array}$ & $\begin{array}{c}100 \\
(0.00)\end{array}$ \\
\hline Agglomeration bonus (AB2) & $\begin{array}{c}22.1 \\
(5.11) \\
\end{array}$ & $\begin{array}{c}9.66 \\
(5.35) \\
\end{array}$ & $\begin{array}{c}91.2 \\
(9.03) \\
\end{array}$ \\
\hline Buyout (BO2) & $\begin{array}{c}34.0 \\
(1.46) \\
\end{array}$ & $\begin{array}{c}20.4 \\
(1.74) \\
\end{array}$ & $\begin{array}{c}100 \\
(0.00) \\
\end{array}$ \\
\hline$V=100, c \in[1,10]$ & Average winning bid & $\begin{array}{l}\text { Average windfall } \\
\text { profits }\end{array}$ & $\begin{array}{c}\text { Average participation } \\
\text { rate }(\%)\end{array}$ \\
\hline Agglomeration bonus $(A B)$ & $\begin{array}{c}29.5 \\
(13.8)\end{array}$ & $\begin{array}{c}20.0 \\
(13.5) \\
\end{array}$ & $\begin{array}{c}75.1 \\
(10.5) \\
\end{array}$ \\
\hline Buyout (BO) & $\begin{array}{c}26.0 \\
(2.59)\end{array}$ & $\begin{array}{c}14.4 \\
(2.89)\end{array}$ & $\begin{array}{c}100 \\
(0.00)\end{array}$ \\
\hline Agglomeration bonus (AB2) & $\begin{array}{c}28.2 \\
(9.68)\end{array}$ & $\begin{array}{c}18.6 \\
(9.47)\end{array}$ & $\begin{array}{c}81.3 \\
(10.4)\end{array}$ \\
\hline Buyout (BO2) & $\begin{array}{c}36.0 \\
(2.59)\end{array}$ & $\begin{array}{c}24.4 \\
(2.89)\end{array}$ & $\begin{array}{c}100 \\
(0.00)\end{array}$ \\
\hline
\end{tabular}

Average winning bids and average windfall profits are displayed for the coalitions, and participation rates are given in percentages for the individual landowners. The results of every treatment and parameter value combination is based on 10,000 auction simulations in which opportunity costs are randomly assigned to the individual landowners from the parameter range depicted in the table. Note that the agglomeration bonus and the buyout costs of 8 or 10 (depending on the max. opportunity costs) are added to the Agglomeration bonus $(\mathrm{AB} / \mathrm{AB} 2)$ and Buyout $(\mathrm{BO} / \mathrm{BO} 2)$ scenarios' winning bids for the ease of comparison. Standard deviations are in parentheses. Windfall profits are calculated for the winning coalition, excluding simulations in which the corridor is not realized in the $\mathrm{BO} / \mathrm{BO} 2$ scenarios (see also Table 4). 
Figure 9. Average coalition windfall profits.

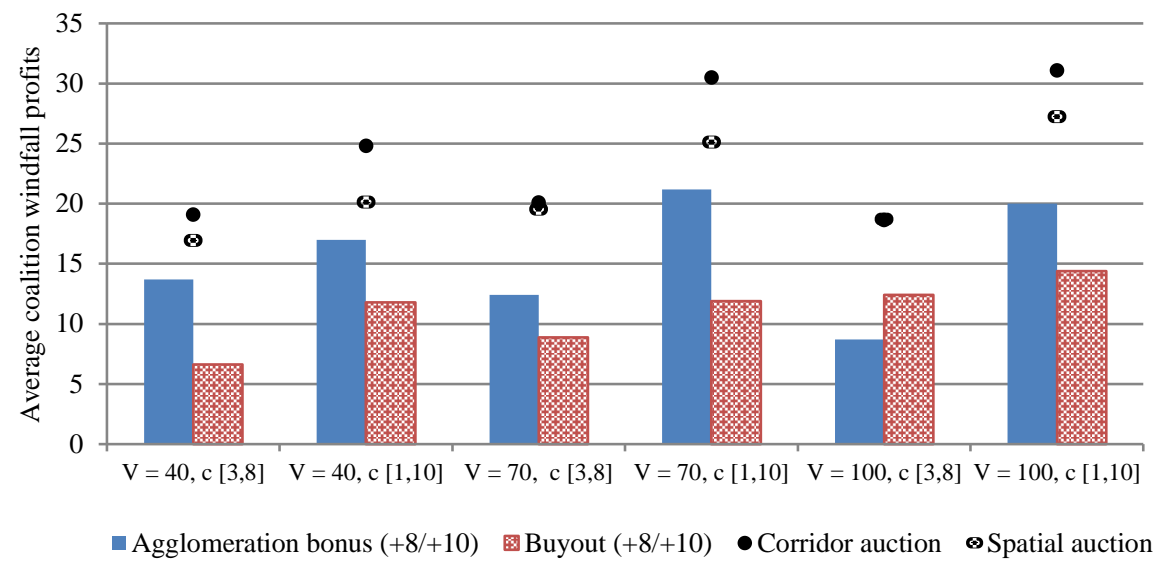

Windfall profits are calculated for the winning coalitions, excluding simulations in which the corridor is not realized in the BO scenario (see also Table 4). Note that the agglomeration bonus/buyout compensation is added to the windfall profits to ease comparison here. The size of the bonus or the compensation is either equal to 8 or 10 depending on the opportunity cost range that applies.

Figure 10. Average coalition windfall profits ( $\mathrm{AB} 2$ and $\mathrm{BO} 2)$.

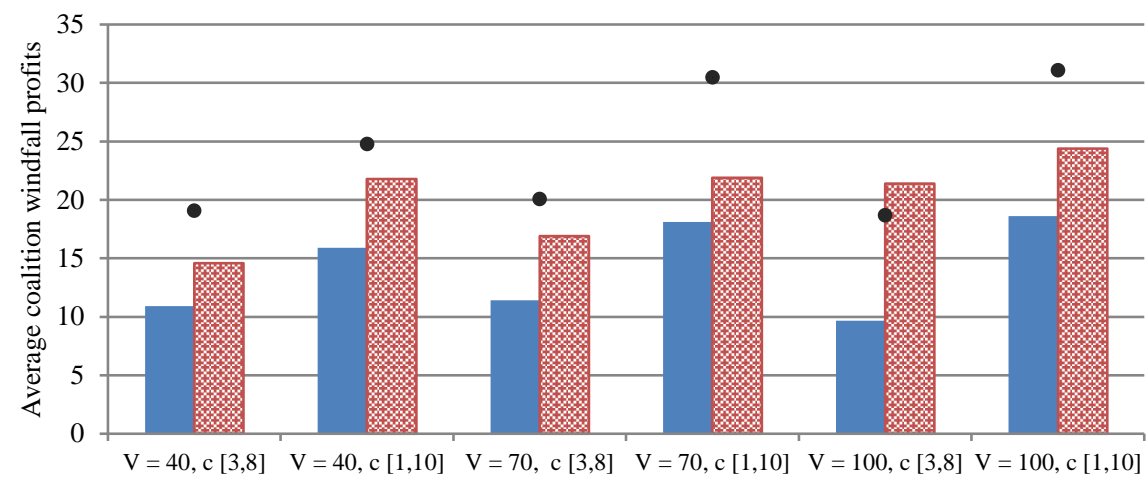

Agglomeration bonus $(+16 /+20)$

图 Buyout $(+16 /+20)$

- Corridor auction

Windfall profits are calculated for the winning coalitions, excluding simulations in which the corridor is not realized in the $\mathrm{BO} 2$ scenario (see also Table 4). Note that the agglomeration bonus/buyout compensation is added to the windfall profits to ease comparison here. The size of the (doubled) bonus or compensation is either equal to 16 or 20 depending on the opportunity cost range that applies. 
Table 4. Detailed simulation results on individual windfall profits (BO/BO2 and $\mathrm{CA})$.

\begin{tabular}{|c|c|c|c|}
\hline Cases & \multicolumn{2}{|c|}{$\begin{array}{l}\text { Simulations without a winning corridor in } \\
\qquad \mathrm{BO} / \mathrm{BO} 2\end{array}$} & $\begin{array}{c}\text { Simulations with landowner } 5 \text { in the } \\
\text { winning coalition in CA }\end{array}$ \\
\hline$V=40, c \in[3,8]$ & \multicolumn{2}{|c|}{68} & 3211 \\
\hline$V=40, c \in[1,10]$ & \multicolumn{2}{|c|}{516} & 2953 \\
\hline$V=70, c \in[3,8]$ & \multicolumn{2}{|c|}{0} & 4077 \\
\hline$V=70, c \in[1,10]$ & \multicolumn{2}{|c|}{19} & 3639 \\
\hline$V=100, c \in[3,8]$ & \multicolumn{2}{|c|}{0} & 4302 \\
\hline$V=100, c \in[1,10]$ & \multicolumn{2}{|c|}{0} & 3978 \\
\hline$V=40, c \in[3,8]$ & Minimum & $\begin{array}{l}\text { Avg. windfall profits of } \\
\text { landowner } 5\end{array}$ & Maximum \\
\hline Corridor auction (CA) & -1 & $\begin{array}{c}2.87 \\
(2.22)\end{array}$ & $\overline{10}$ \\
\hline Buyout (BO) & 0 & $\begin{array}{c}2.50 \\
(1.72)\end{array}$ & 5 \\
\hline Buyout (BO2) & 8 & $\begin{array}{r}10.5 \\
(1.72) \\
\end{array}$ & 13 \\
\hline$V=40, c \in[1,10]$ & Minimum & $\begin{array}{l}\text { Avg. windfall profits of } \\
\text { landowner } 5\end{array}$ & Maximum \\
\hline Corridor auction (CA) & -1 & $\begin{array}{c}4.04 \\
(2.84)\end{array}$ & 12 \\
\hline Buyout (BO) & 0 & $\begin{array}{c}4.55 \\
(2.84)\end{array}$ & 9 \\
\hline Buyout (BO2) & 10 & $\begin{array}{c}14.6 \\
(2.84) \\
\end{array}$ & 19 \\
\hline$V=70, c \in[3,8]$ & Minimum & $\begin{array}{l}\text { Avg. windfall profits of } \\
\text { landowner } 5\end{array}$ & Maximum \\
\hline Corridor auction (CA) & 0 & $\begin{array}{c}3.53 \\
(2.66)\end{array}$ & 20 \\
\hline Buyout (BO) & 0 & $\begin{array}{c}2.48 \\
(1.70)\end{array}$ & 5 \\
\hline Buyout (BO2) & 8 & $\begin{array}{c}10.5 \\
(1.70)\end{array}$ & 13 \\
\hline$V=70, c \in[1,10]$ & Minimum & $\begin{array}{l}\text { Avg. windfall profits of } \\
\text { landowner } 5\end{array}$ & Maximum \\
\hline Corridor auction (CA) & -1 & $\begin{array}{c}5.96 \\
(4.26)\end{array}$ & 22 \\
\hline Buyout (BO) & 0 & $\begin{array}{c}4.51 \\
(2.86)\end{array}$ & 9 \\
\hline Buyout (BO2) & 10 & $\begin{array}{c}14.5 \\
(2.86)\end{array}$ & 19 \\
\hline$V=100, c \in[3,8]$ & Minimum & $\begin{array}{l}\text { Avg. windfall profits of } \\
\text { landowner } 5\end{array}$ & Maximum \\
\hline Corridor auction (CA) & 0 & $\begin{array}{c}3.31 \\
(2.24)\end{array}$ & 29 \\
\hline Buyout (BO) & 0 & $\begin{array}{c}2.49 \\
(1.72)\end{array}$ & 5 \\
\hline Buyout (BO2) & 8 & $\begin{array}{c}10.5 \\
(1.72)\end{array}$ & 13 \\
\hline
\end{tabular}


Table 4. Continued.

\begin{tabular}{l|ccc}
$\qquad$ & Minimum & $\begin{array}{c}\text { Avg. windfall profits of } \\
\text { landowner 5 }\end{array}$ & Maximum \\
\hline \hline Corridor auction $(C A)$ & 0 & 6.42 & 32 \\
& 0 & $4.30)$ & 9.52 \\
\hline Buyout $(B O)$ & 10 & $(2.88)$ & 19 \\
\hline Buyout $(B O 2)$ & & 14.5 & $(2.88)$ \\
& & & 320 \\
\hline
\end{tabular}

Results are based on simulations in which landowner 5 was part of the winning coalition. Winning frequencies of landowner 5 in CA and the frequency of the corridor being realized in $\mathrm{BO} / \mathrm{BO} 2$ for the different cases is depicted in the top of the table. Standard deviations are in parentheses. Average windfall profits of landowner 5 (given that he/she is part of a winning coalition in the CA scenario) are depicted with their minimum and maximum values. Windfall profits of landowner 5 in the $\mathrm{BO}$ and $\mathrm{BO} 2$ scenarios are given assuming that landowner 5 always accepts the buyout compensation. The minimum windfall profits are lower than zero in a few cases since we applied only one iteration for the participation decision. 